This is a post-peer-review, pre-copyedit version of an article published in Drug Delivery and Translational Research. The final authenticated version is available online at: https://doi.org/10.1007/s13346-020-00843-Z 


\title{
Corticosteroids in ophthalmology: drug delivery innovations, pharmacology, clinical applications and future perspectives
}

\author{
Sherif A. Gaballa ${ }^{1}$, Uday B. Kompella ${ }^{2}$, Omar Elgarhy ${ }^{1}$, Ali M Alqahtani ${ }^{3}$, Barbara Pierscionek ${ }^{4}$, Raid G Alany ${ }^{5,6}$, Hamdy
} Abdelkader ${ }^{1,7 *}$

${ }^{1}$ Department of Pharmaceutics, Faculty of Pharmacy, Mania University, Mania, Egypt, ${ }^{2}$ Departments of Pharmaceutical Sciences, Ophthalmology, and Bioengineering, University of Colorado Anschutz Medical Campus, Aurora, CO 80045

${ }^{3}$ Department of Pharmacology, College of Pharmacy, King Khalid University, Abha-61441, Kingdom of Saudi Arabia, ${ }^{4}$ School of Life Science and Education, Staffordshire University, College Road, Stoke-on-Trent ST4 2DE, UK

${ }^{5}$ Drug Discovery, Delivery and Patient Care Theme, Faculty of Science, Engineering and Computing, Kingston University, Penrhyn Road, Kingston upon Thames, Surrey. KT1 2EE

${ }^{6}$ School of Pharmacy, The University of Auckland, Auckland, New Zealand

${ }^{7}$ Department of Pharmaceutics, Faculty of Pharmacy, Deraya University, Minia, Egypt

\section{Abstract}

Corticosteroids remain the mainstay of the treatment for various ocular conditions affecting the ocular surface, anterior and posterior segments of the eye due to their anti-inflammatory, anti-oedematous and anti-neovascularization properties. Prednisolone, prednisolone acetate, dexamethasone, triamcinolone acetonide, fluocinolone acetonide, and loteprednol etabonate are amongst the most widely used ophthalmic corticosteroids. Corticosteroids differ in their activity and potency in the eye due to their inherent pharmacological and pharmaceutical differences.

Different routes and regimens are available for ocular administration of corticosteroids. Conventional topical application to the eye is the route of choice when targeting diseases affecting the ocular surface and anterior segment, while periocular, intravitreal, and suprachoroidal injections can 
be potentially effective for posterior segment diseases. Corticosteroid-induced intraocular pressure elevation and cataract formation remain the most significant local risks following topical as well as systemic corticosteroid administration. Invasive drug administration via intracameral, subconjunctival and intravitreal injection can enhance ocular bioavailability and minimize dose and dosing frequency of administration, yet may exacerbate ocular side effects of corticosteroids. This review provides a critical appraisal of the ophthalmic uses of corticosteroid, routes of administration, drug delivery fundamentals and novel ocular implantable steroids delivery systems, factors influencing side effects and future perspectives for ocular corticosteroid therapy.

Graphical abstract

\section{Keywords}

Corticosteroids, eye diseases, ocular drug delivery, steroids intracanalicular inserts, ocular hypertension, cataract, delivery systems.

\section{Correspondence}

Hamdy Abdelkader, PhD, FHEA

Faculty of Pharmacy, Minia University, Minia, Egypt

Email: h.abdelkader@mu.edu.eg

Mobile: +201008116835 


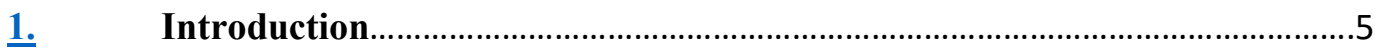

2. Corticosteroids: structure and physicochemical properties...................

3. Corticosteroids: pharmacotherapy ….................................................15

4. Routes of ocular corticosteroid administration and pharmacokinetics.... 16

4.1. Topical ocular administration........................................................................17

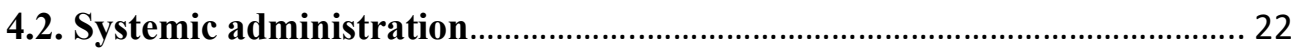

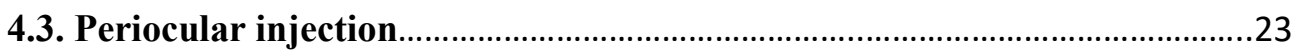

4.3.1. Subconjunctival injection....................................................................23

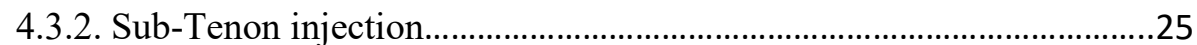

4.3.3. Retrobulbar injection...........................................................................25

4.3.4. Peribulbar injection................................................................................2.

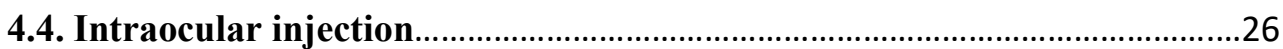

4.4.1. Suprachoroidal injection...................................................................2

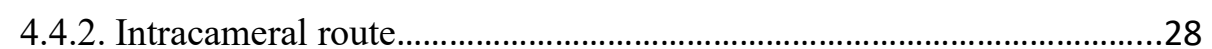

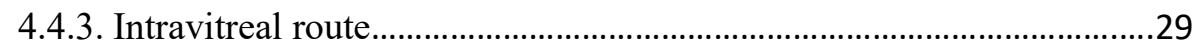

5. Ophthalmic adverse effects of glucocorticoids ..........................35

5.1. Corticosteroid-induced IOP elevation (ocular hypertension)

5.1.1. Mechanism of corticosteroid-induced IOP

5.1.2. Factors affecting corticosteroid-induced IOP 
7. Future perspectives........................................................................................ 4

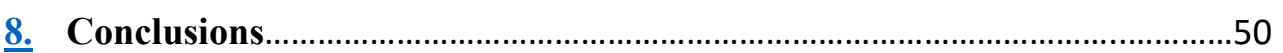

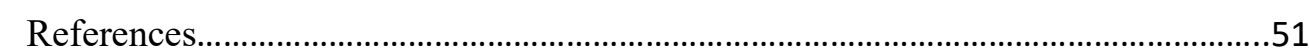

\section{Introduction}

This review provides an in-depth discussion of ophthalmic corticosteroids including clinical uses, routes of administration, drug delivery fundamentals and delivery systems, factors influencing ocular side effects and future perspectives for drug delivery scientists, pharmacists, ophthalmologists and other health care professionals.

Corticosteroids are amongst the most potent and effective anti-inflammatory medications. Consequently, corticosteroids are widely prescribed for the management of various ocular diseases, which can be classified into two main groups (Figure 1). Diseases affecting the anterior segment of the eye including inflammation caused by surgery, injury, or other conditions, eye swelling, redness, itching, and pain, conjunctivitis [1], uveitis [2], dry eye [3], scleritis and episcleritis [4] and those affecting the posterior segment of the eye including non-infectious posterior segment uveitis, macular edema following branched/central retinal vein occlusion, diabetic macular edema (DME) in patients post-cataract surgery [5, 6], DME in patients who have a history of intraocular pressure (IOP) elevation following corticosteroid dosing, diabetic retinopathy (DR) [7], , age-related macular degeneration (AMD) [8] and postoperative macular edema [9]. 
Dexamethasone, difluprednate, fluocinolone acetonide, fluorometholone, loteprednol etabonate, prednisolone, prednisolone acetate and triamcinolone acetonide are the key corticosteroids for ophthalmic use. They can be administered through topical, systemic, periocular and intraocular routes to treat eye diseases. Corticosteroids are available in a variety of dosage forms including solutions, suspensions, emulsions, ointments and slow-release implants for use based on the targeted disease and its location inside the eye.

The anti-inflammatory effect of corticosteroids is primarily a result of the modulation of gene expression by transrepression and upregulation following their binding to the cytosolic glucocorticoid receptor. The therapeutic effects of corticosteroids will be discussed in detail later in section 3. Corticosteroids exert anti-neovascular effects and inhibit the formation of new blood vessels. These effects may be significant for treating AMD and DR [10-12]. Corticosteroids are considered superior anti-inflammatory drugs for treating ocular inflammations due to their potency and efficacy [13] and they may be a more appropriate treatment alternative for anti-vascular endothelial growth factor (anti-VEGF) agents especially in DME patients awaiting cataract surgery or in pseudophakes [10]. However, corticosteroids are not devoid of serious ocular side effects such as elevation of intraocular pressure, glaucoma, cataract, increased susceptibility to infection, and reduced wound healing [14-16]. 


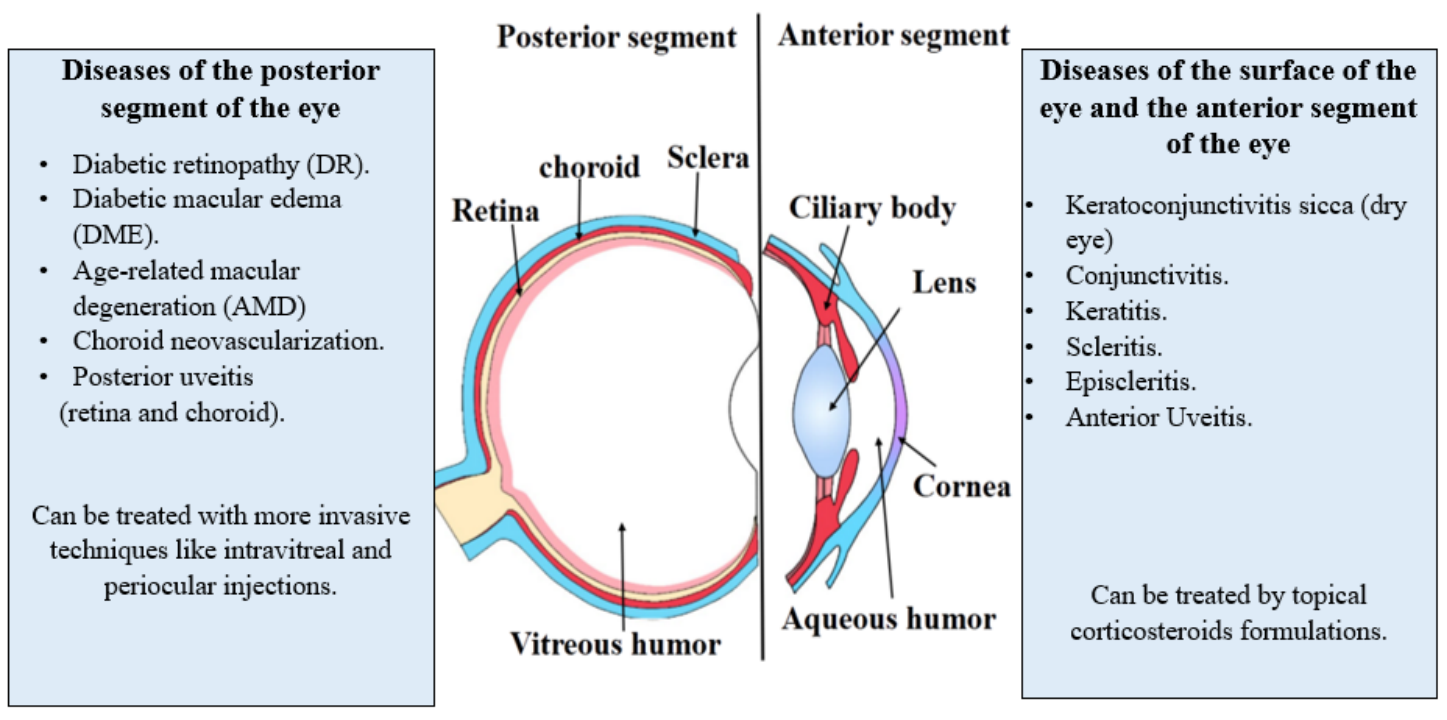

Figure 1 Various ocular surface, anterior and posterior eye diseases that can be treated with corticosteroids.

\section{Corticosteroids: structure and physicochemical properties}

All corticosteroids share a basic sterane (steroid nucleus) structure with 21 carbon atoms and four rings. Figure 2 shows the chemical structures of commonly used ophthalmic corticosteroids. Structural modifications produce new compounds with different physicochemical properties and biological potencies [17]. Table 1 outlines the physicochemical properties, log partition coefficient (P), novel ophthalmic formulations, and the commercially available dosage forms of commonly used corticosteroids for the treatment of ophthalmic diseases. 
Most corticosteroids with anti-inflammatory properties are characterized by the presence of hydroxyl groups at C17 in $\alpha$ - position, a double bond between $\mathrm{C} 4$ and $\mathrm{C} 5$, a ketone group at $\mathrm{C} 3$ and an oxygen functional group at $\mathrm{C} 11$ [18, 19]. With the addition of double bonds between $\mathrm{C} 1$ and $\mathrm{C} 2$, such as those present in prednisolone, there is a decrease in degradation rate. Further, the addition of a fluorine atom at C9 led to enhanced antiinflammatory activity as is the case with triamcinolone [18]. The presence of furoate ester moiety in C-17 $\alpha$ position increases the affinity of corticosteroids to the glucocorticoid receptor. Fluticasone furoate and mometasone furoate are examples of highly potent corticosteroids with the lipophilic moiety $[20,21]$.

Further, replacement of the hydroxyl group at the $\mathrm{C} 21$ in prednisolone with an acetate group resulted in the formation of the prodrug prednisolone acetate. The acetate form of prednisolone is more lipophilic and showed enhanced corneal permeation compared to prednisolone and its phosphate form [22]. Also, the presence of acetonide group at C16 and C17 leads to increased lipophilicity for triamcinolone acetonide and fluocinolone acetonide.

Majority of ophthalmic products are solutions. However, corticosteroids are marketed as solutions, suspensions, emulsions and implants for ophthalmic use, with the majority of the products being more complex than simple aqueous solutions. This is because corticosteroids typically have low water solubility. Thakur et al. [23] studied the solubility of corticosteroids in phosphate buffer saline containing $0.5 \% \mathrm{w} / \mathrm{v}$ carboxymethyl cellulose. The solubility of the studied corticosteroids was in the following order: prednisolone $(0.243 \mathrm{mg} / \mathrm{ml}>$ dexamethasone $(0.16 \mathrm{mg} / \mathrm{ml}>$ fluocinolone acetonide $(0.05 \mathrm{mg} / \mathrm{ml})>$ triamcinolone acetonide $(0.021 \mathrm{mg} / \mathrm{ml})$ [23]. The water solubility of fluocinolone acetonide was found to be only $4 \%$ that for dexamethasone, due to the presence of the acetonide group $[24,25]$. In addition, the presence of phosphate moiety at $\mathrm{C} 21$ allows the formation of sodium salts of corticosteroids with improved water solubility. Corticosteroids can be broadly divided into water-soluble and poorly water-soluble. Dexamethasone sodium phosphate and prednisolone sodium phosphate are two examples of water soluble corticosteroids[26, 27]. Poorly water-soluble corticosteroids include prednisolone, prednisolone acetate, triamcinolone acetonide and fluocinolone 
acetonide. Water soluble corticosteroid forms can be formulated as ophthalmic solutions for use as eye drops. Poorly soluble forms are generally administered as ophthalmic suspensions or emulsions (Table 1). Due to the presence of hydroxyl groups at X17 and R21 positions, dexamethasone is classified as a slightly water-soluble corticosteroid (Figure 2).

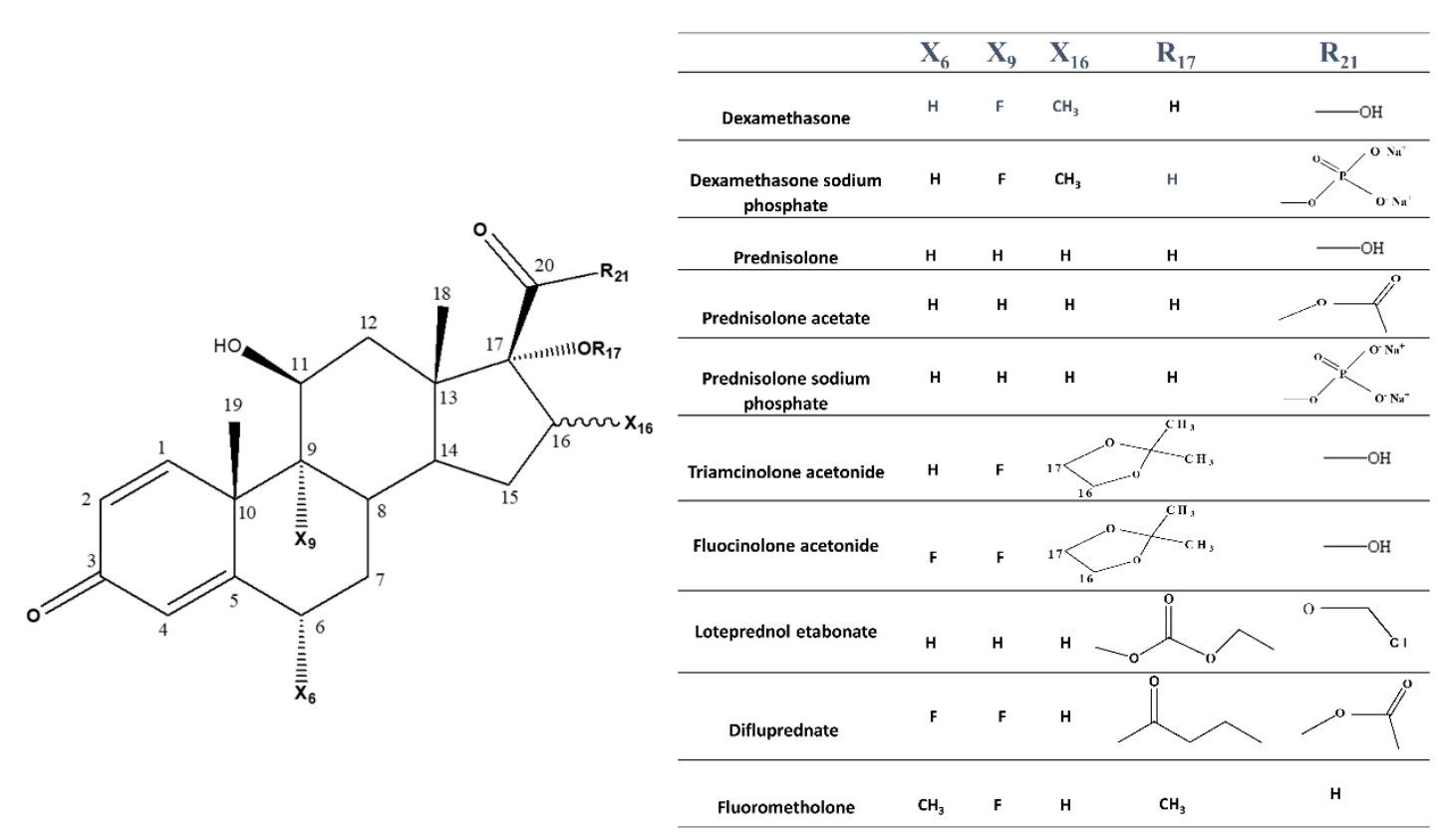

Figure 2 Structures of the most commonly used corticosteroids for ocular application. 
Interestingly, corticosteroids with low solubility are the drugs of choice for polymeric slow-release delivery systems such as Ozurdex ${ }^{\circledR}$ (Dexamethasone-based implant) and Iluvien ${ }^{\circledR}$ (fluocinolone acetonide-based implant) [28]. Ozurdex ${ }^{\circledR}$ (a bio-erodible implant) is recommended for intravitreal injection every 6 months; Iluvien ${ }^{\circledR}$ (a non-bioerodible implant) is injected every 36 months. This marked long duration of action of Iluvien ${ }^{\circledR}$ has been partly ascribed to the lower solubility of fluocinolone acetonide compared to dexamethasone, in addition to the non-degradable polymer and slower zero-order release rate for fluocinolone acetonide [29, 30].

e Intravitreal injection of triamcinolone acetonide is an effective treatment for various ocular inflammatory diseases. Kenalog ${ }^{\circledR}-40$ injection manufactured by Bristol Myers Squibb, has not been approved for intraocular use and its use in ophthalmology has been off-label [31]. This injectable dosage form, when administered intraocularly, has resulted in rare cases (yet clinically significant) of non-bacterial endophthalmitis (around 1\%), which was linked to the presence of inadequate excipients for intraocular administration such as benzyl alcohol (a preservative). Benzyl alcohol is suspected of being an irritant $[32,33]$. Hence, Kenalog ${ }^{\circledR}-40$ is not indicated for intraocular administration by the European Union [34]. Preservative-free Triesence ${ }^{\circledR}$ and Trivaris ${ }^{\circledR}$, two ophthalmic suspensions of triamcinolone acetonide were developed and approved for intravitreal injections (Table 3) [30].

The natural logarithm of octanol-water partition coefficient $(\log \mathrm{P})$ is a useful physicochemical parameter that represents drug lipophilicity and drug affinity for biological membranes including corneal epithelium. Table 1 shows $\log \mathrm{P}$ values of corticosteroids commonly used in 
ophthalmology. Log P varies according to the functional group substitution of the corticosteroids and ionization state. Esters such as prednisolone acetate $(\log \mathrm{P}=2.4)$ are more lipophilic than the parent weak acid (prednisolone, $\log \mathrm{P}=1.6)[35,36]$. On the other hand, phosphate salts s such as dexamethasone sodium phosphate ( $\log$ P 1.5$)$ are more hydrophilic compared to the parent drug $(\log \mathrm{P} 1.83)$ as shown in Table 1 . Dexamethasone sodium phosphate and prednisolone sodium phosphate, in their ionized form, showed less corneal permeation compared to their weak acids counterparts (dexamethasone and prednisolone) when administered as eye drops. Advanced drug delivery systems such as niosomes and liposomes of these sodium salts have demonstrated enhanced corneal permeation compared with the control solutions of the corticosteroid sodium salts [26, 37].

Table 1 Ocular corticosteroids, their solubility, log partition coefficients $(\mathrm{P})$, novel pharmaceutical formulations and approved commercial dosage forms.

\begin{tabular}{|c|c|c|c|c|}
\hline & $\begin{array}{l}\text { Properties of } \\
\text { synthetic } \\
\text { corticosteroid }\end{array}$ & $\log P$ & $\begin{array}{c}\text { Novel } \\
\text { Pharmaceutical } \\
\text { formulations }\end{array}$ & $\begin{array}{c}\text { Marketed } \\
\text { dosage form }\end{array}$ \\
\hline Dexamethasone & $\begin{array}{l}\text { Practically water in } \\
\text { soluble }(0.16 \text { mg/ml }) \\
{[38] \text { with a higher }} \\
\text { affinity to glucocorticoid } \\
\text { receptor [39]. Its } \\
\text { aqueous humor } \mathrm{t}_{1 / 2} \text { is } \\
\text { about (3-6) } \mathrm{h}[40] \text { and } \\
\text { requires frequent } \\
\text { administration. }\end{array}$ & $1.8[36,41]$ & $\begin{array}{l}\text { Hydrogel [42]. } \\
\text { Microemulsion [43]. } \\
\text { Cubosomes [39]. }\end{array}$ & $\begin{array}{l}\text { Ozurdex }{ }^{\circledR} \text { implant } \\
\text { Maxidex }{ }^{\circledR} 0.1 \% \\
\text { suspension. }\end{array}$ \\
\hline
\end{tabular}




\begin{tabular}{|c|c|c|c|c|}
\hline $\begin{array}{c}\text { Dexamethasone } \\
\text { sodium phosphate }\end{array}$ & $\begin{array}{l}\text { Synthetic sodium salt of } \\
\text { dexamethasone } \\
\text { phosphate, which is } \\
\text { highly water-soluble } \\
(1.52 \mathrm{mg} / \mathrm{ml} \quad \text { [26], } \\
\text { hydrolyzed into } \\
\text { dexamethasone, with } \\
\text { poor corneal penetration } \\
\text { (ionized form) and used } \\
\text { mainly for anterior } \\
\text { segment inflammation in } \\
\text { novel delivery systems } \\
\text { to improve corneal } \\
\text { permeability [26, 27, } \\
44] .\end{array}$ & $1.5[36]$ & $\begin{array}{l}\text { Liposome }[26] \text {. } \\
\text { Hydrogel contact lenses } \\
{[45] .} \\
\text { Gel }[46] .\end{array}$ & $\begin{array}{l}\text { Dexapar }^{\circledR} \text {, } \\
\text { Dexachlor } \\
\text { and } \\
\text { Dropodex } \\
\text { eye drops }\end{array}$ \\
\hline Prednisolone & $\begin{array}{l}\text { Cortisol derivative } \\
\text { commonly used in } \\
\text { acetate and phosphate } \\
\text { form [47]. Very slightly } \\
\text { soluble }(0.243 \mathrm{mg} / \mathrm{ml} \text { at } \\
25 \mathrm{C}) \text { in water }[41,48] \text {. }\end{array}$ & $1.6[41,49]$ & $\begin{array}{l}\text { Niosomes [50]. } \\
\text { Nanoparticle-laden } \\
\text { contact lenses [47]. } \\
\text { Nanocapsules [51]. }\end{array}$ & $\begin{array}{l}\text { Pred Mild }{ }^{\circledR} 0.12 \% \\
\text { suspension } \\
\text { Orchapred }{ }^{\circledR} \text { suspension }\end{array}$ \\
\hline $\begin{array}{l}\text { Prednisolone } \\
\text { acetate }\end{array}$ & $\begin{array}{l}\text { Lipophilic } r \text { acetate } \\
\text { prodrug, which is } \\
\text { hydrolyzed } \\
\text { prednisolone } \quad \text { to } \\
\text { form). It is practically } \\
\text { insoluble in water. It has } \\
\text { higher corneal } \\
\text { permeability, less potent } \\
\text { than dexamethasone [52, } \\
\text { 53]. }\end{array}$ & $2.4[54]$ & $\begin{array}{l}\text { Niosomes [50]. } \\
\text { Eye drop [55]. } \\
\text { Liposomes [56]. } \\
\text { Hydrogel contact lenses } \\
{[57]}\end{array}$ & $\begin{array}{l}\text { Kapimox-P suspension } \\
\text { Pred fort } 1 \% \text { suspension }\end{array}$ \\
\hline
\end{tabular}




\begin{tabular}{|c|c|c|c|c|}
\hline $\begin{array}{l}\text { Prednisolone } \\
\text { sodium phosphate }\end{array}$ & $\begin{array}{l}\text { Sodium phosphate salt } \\
\text { of prednisolone with } \\
\text { lower corneal } \\
\text { penetration capability } \\
\text { than acetate salt (ionized } \\
\text { form) [27]. It is freely } \\
\text { soluble in water (soluble } \\
1 \text { in } 3 \text { in water), and } \\
\text { mostly formulated as } \\
\text { solution [41]. }\end{array}$ & $1.15[36]$ & $\begin{array}{l}\text { Niosomes [50]. } \\
\text { Gel 1\% [58]. }\end{array}$ & $\begin{array}{l}\text { Predsol }^{\circledR} 1 \% \\
\text { eye drops }\end{array}$ \\
\hline $\begin{array}{l}\text { Triamcinolone } \\
\text { acetonide }\end{array}$ & $\begin{array}{l}\text { A corticosteroid with a } \\
\text { fluorine atom in the } \\
\text { ninth position. It is very } \\
\text { slightly soluble in water } \\
\text { triamcinolone acetonide } \\
(21 \mu \mathrm{g} / \mathrm{ml}) \text { [59]and more } \\
\text { potent than } \\
\text { triamcinolone [60]. It } \\
\text { remains in the vitreous } \\
\text { for much longer than } \\
\text { other corticosteroids and } \\
\text { formulated as an } \\
\text { intravitreal implant [61]. }\end{array}$ & $2.31[54]$ & $\begin{array}{l}\text { Intravitreal injection } \\
\text { [61]. } \\
\text { Liposomes [62]. }\end{array}$ & $\begin{array}{l}\text { Trivaris }{ }^{\circledR} \text { suspension } \\
\text { Triesence }{ }^{\circledR} \text { suspension } \\
\text { for intravitreal injection }\end{array}$ \\
\hline $\begin{array}{l}\text { Fluocinolone } \\
\text { acetonide }\end{array}$ & $\begin{array}{l}\text { A corticosteroid with } \\
\text { fluorine instead of a } \\
\text { hydrogen atom in the } \\
\text { sixth and ninth positions. } \\
\text { It is highly lipophilic and } \\
\text { practically insoluble in } \\
\text { water }(0.05 \mathrm{mg} / \mathrm{ml}) \text { [ } 63 \text {, } \\
\text { 64]. Assessed as an } \\
\text { intravitreal implant [65] } \\
\text { and marketed as an } \\
\text { intravitreal suspension. }\end{array}$ & $2.5[36]$ & $\begin{array}{l}\text { Intravitreal implant [66] } \\
\text { Liposomes [67] }\end{array}$ & $\begin{array}{l}\text { Retisert }{ }^{\circledR} \text { implant } \\
\text { Iluvien }^{\circledR} \text { implant }\end{array}$ \\
\hline
\end{tabular}




\begin{tabular}{|c|c|c|c|c|}
\hline $\begin{array}{l}\text { Loteprednol } \\
\text { etabonate }\end{array}$ & $\begin{array}{l}\text { Diester bond at } \mathrm{C}_{17} \text { with } \\
\text { increased lipophilicity } \\
\text { (water solubility } 0.5 \\
\mu \mathrm{g} / \mathrm{ml} \text { ) and higher } \\
\text { corneal penetration [68]. } \\
\text { It is hydrolyzed in } \\
\text { cornea and aqueous } \\
\text { humor into its active } \\
\text { form with lower side } \\
\text { effects [69]. }\end{array}$ & $3.04[68]$ & $\begin{array}{l}\text { Gel } 0.5 \%[70] . \\
\text { Suspension } 0.2 \% \text { [71]. }\end{array}$ & Lotemax ${ }^{\circledR}$ eye drops \\
\hline Fluorometholone & $\begin{array}{l}\text { Synthetic fluorinated } \\
\text { corticosteroids with } \\
\text { acetate group at } \mathrm{C}_{17} \\
\text { Practically } \\
\text { insoluble }(0.03 \mathrm{mg} / \mathrm{ml}) \\
{[72] .}\end{array}$ & $2.0[36]$. & $\begin{array}{l}\text { Polymeric Micelle eye } \\
\text { drop[72] } \\
\text { Suspension } 0.1 \%[73]\end{array}$ & $\begin{array}{l}\text { Flucon }{ }^{\circledR} \text { suspension } \\
\text { FML }^{\circledR} \text { ointment }\end{array}$ \\
\hline Difluprednate & $\begin{array}{l}\text { It is a butyrate ester of } \\
\text { difluoro prednisolone } \\
\text { acetate which is rapidly } \\
\text { deacetylated in the } \\
\text { aqueous humor into } \\
\text { active metabolite } \\
\text { (difluoro prednisolone } \\
\text { butyrate). Highly } \\
\text { lipophilic due to the } \\
\text { presence of butyrate and } \\
\text { acetate moieties [74]. } \\
\text { Practically water } \\
\text { insoluble (0.01 mg/ml) } \\
\text { [75]. }\end{array}$ & $3.4[75]$ & $\begin{array}{l}\text { Ophthalmic emulsion } \\
{[76]}\end{array}$ & $\begin{array}{l}\text { Visipred }{ }^{\circledR} \text { ophthalmic } \\
\text { emulsion } \\
\text { Diflustero }{ }^{\circledR} \text { ophthalmic } \\
\text { emulsion } \\
\begin{array}{l}\text { Durezol }{ }^{\circledR} \text { ophthalmic } \\
\text { emulsion }\end{array}\end{array}$ \\
\hline
\end{tabular}




\section{Corticosteroids: brief overview of pharmacology with emphasis on inflammatory conditions of eye}

Ocular inflammation, if untreated, could lead to temporary or permanent vision loss and involves local modification in blood flow and an attack on ocular tissue by immune cells and different inflammatory mediators [77, 78].Common clinical signs and symptoms include such as redness, itching, pain and swelling [79].

Corticosteroids have been used for treating ocular inflammation for around five decades, since the systemic administration of an adrenocorticotrophic hormone derived from the hypophyseal system led to a considerable outcome improvement in patients with uveitis [80]. They exert their anti-inflammatory effects by blocking the cascading inflammatory mechanisms including the biosynthesis of eicosanoid; the release and activity of cytokines, chemotactic proteins and matrix metalloproteinases [81]; and accumulation of inflammatory proteins such as vascular endothelial growth factor (VEGF) and cyclooxygenase 2 by decreasing the stability of their mRNA [82]. Corticosteroids exert anti-inflammatory activities via genomic and nongenomic effects $[19,82]$.

The genomic mechanism produces effects through glucocorticoid receptors (GR). Within the cytosol; corticosteroids bind with high affinity to the GR and the active corticosteroid-GR complex translocates into the nucleus. Herein, genomic effects involve the up-regulation of anti-inflammatory proteins expression such as lipocortin1 and interleukin-10 and suppression of the expression of proinflammatory proteins such as nuclear factor-kappa-B (NF-kappa-B) and activator protein-1 (AP-1). The nongenomic mechanism exerts rapid effects on immune cells and regulate cell adhesion;[83] and involves the inhibition of dilatation of the blood vessels, vascular permeability and leukocyte migration $[82,84]$ through the inhibition of phospholipase $\mathrm{A}_{2}$. Generation of novel corticosteroids that exert their effect solely through the nongenomic pathway has potential for future research [85] and is discussed further in this review.

The detailed mechanisms by which corticosteroids benefit AMD and DME are still being elucidated and an anti-neovascularization mechanism has been proposed [11]. Corticosteroids can stabilize and reconstitute the blood-retinal barrier, positively 
impacting Starling's equilibrium by capillary constriction and VEGF downregulation [86]. Ayalasomayajula et al. [12] showed that fluocinolone acetonide inhibits the expression of VEGF in RPE cells through glucocorticoid receptors and also inhibits the TNF- $\alpha$-induced angiogenesis in hen's chorioallantoic membrane [12].

\section{Routes of ocular corticosteroid administration and pharmacokinetics.}

Different drug delivery routes have been employed for the management of ocular conditions depending on the disease site. Drugs with high corneal permeability and drug products with prolonged precorneal retention are useful in improving bioavailability of the ocular surface and anterior segment [87]. Generally, topical drug delivery is most suitable for localizing drug effects and minimizing systemic adverse effects for diseases of the anterior eye [88]. For diseases affecting the posterior segment, different strategies have been employed to increase or prolong drug efficacy. These include intraocular injections to localize the drug in the posterior of the eye and administration in implant form sustains the drug release and prolongs the duration of therapy [89]. Systemic administration may also be used to reach the target- tissues in the posterior segment of the eye via the systemic circulation [90].

Generally, ocular drug delivery of corticosteroids can be achieved via different routes as illustrated in Figure 3. Key routes of administration and the associated drug pharmacokinetic considerations are briefly discussed below. 


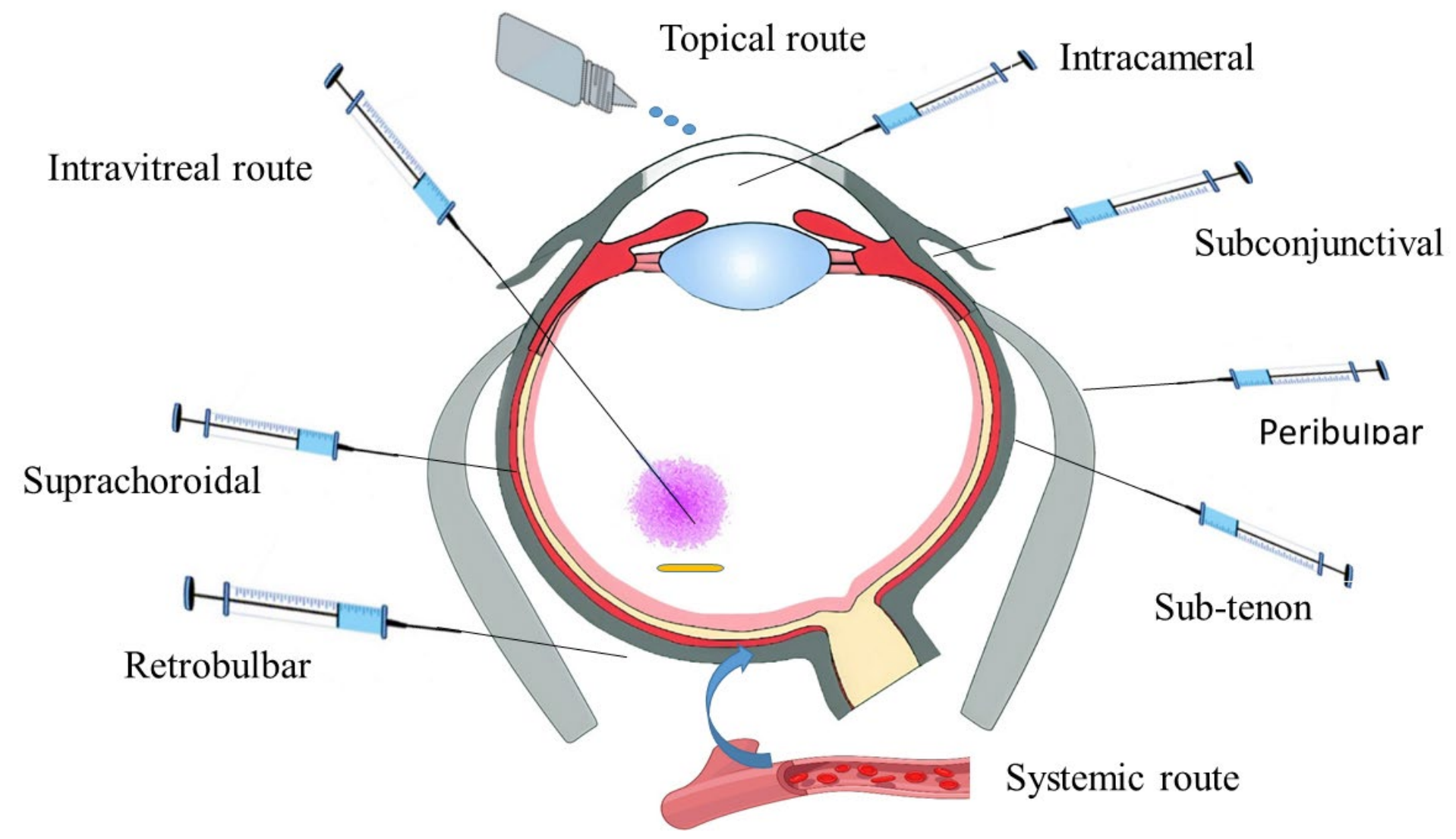

Figure 3 Routes of administration for ocular delivery of corticosteroids.

\subsection{Topical ocular administration}

Topical application is most favored route for ocular drug delivery, especially when targeting diseases affecting the ocular surface and anterior segment of the eye. It is accomplished by directly applying drug formulations on the ocular surface (Figure 3) [91]. It is non-invasive with reasonable patient adherence. Topical administration is likely to minimize the systemic side effects and allows the use of a relatively high drug concentration sufficiently close to the affected ocular tissue compared to systemic administration [17, 92]. For topical ocular delivery of corticosteroids, many conventional formulations including aqueous eye drop formulations such as simple 
solutions, suspensions, gels and emulsions as well as ointments have been employed $[93,94]$. However, the major drawback of these conventional liquid formulations is the limited ocular bioavailability [95, 96]. This could be attributed to multiple physiological barriers including epithelial and connective tissue barriers, tear turnover, nasolacrimal drainage of the instilled dose and potentially poor in vivo dissolution of practically insoluble corticosteroids (Table 1) [91, 97, 98]. Nasolacrimal drainage and systemic absorption via the nose, GI tract and the conjunctival blood vessels are the main reasons for induced systemic toxicity of topically applied ophthalmic medications [99-101].

Drug lipophilicity can contribute to the extent of systemic drug absorption after topical instillation of ophthalmic eye drops. The contribution of nasolacrimal pathway to systemic drug absorption has been reported to decrease with increasing lipophilicity of drug [101]. Ophthalmic ointments or viscous gels are also available for topical administration of corticosteroids such as fluorometholone, dexamethasone and loteprednol etabonate. While these formulations reduce drug drainage from the eye surface, they cause transient blurring of vision and matted eye lids. Other formulations factors that are likely to affect ocular bioavailability of water-insoluble forms of corticosteroids include particle size and viscosity of the vehicle. These two key factors are likely to have an impact on in vivo dissolution time and drug loss from the surface of the eye through the nasolacrimal drainage system.

More recently, the effects of particle size and viscosity on the area under the aqueous humor concentration-time curve $\left(\mathrm{AUC}_{0-24 \mathrm{~h}}\right)$ were investigated as a measure of ocular bioavailability, of three budesonide suspension formulations. The three suspension formulations were all isotonic but formulated with low $(4 \mathrm{cP})$ and high $(50 \mathrm{cP})$ viscosity values, and different particle sizes (nanosize versus micorsize particles). The $\mathrm{AUC}_{0-24 \mathrm{~h}}$ values were 1.064, 1.013 and 1.630 for NP-LV (particle size: $0.71 \mu \mathrm{m}$ and viscosity: 4.89 Pc), MP-LV (particle size: $1.95 \mu \mathrm{m}$ and viscosity: $4.92 \mathrm{cP}$ ) and MP-HV (particle size: $1.98 \mu \mathrm{m}$ and viscosity: $53 \mathrm{cP}$ ). These results indicate that the viscosity rather than particle size has a more pronounced effect on the ocular bioavailability of budesonide. Precorneal residence time and retention of the formulation on the surface of the eye is more important than particle size. Formulation of corticosteroids as microsuspensions with high-viscosity resulted in more ocular bioavailability than their low-viscosity counterpart [102].On the other hand, topical corticosteroid administration could 
develop faster (few hours to several days) ocular adverse effects especially a rise in IOP compared with other routes of administration, such as systemic and inhaled corticosteroids which could take months to years to develop an appreciable rise in IOP [103-105]. For example, it has been reported that topical administration of corticosteroids for 4-6 weeks can result in elevation of IOP $>16 \mathrm{mmHg}$ in $5 \%$ and between 6-15 mmHg in 30\% of the treated population [105]. The typical pulsatile (high local concentration and repeated instillations on the surface of the eye) mode of administration of conventional corticosteroids suspensions and eye drops could be the major contributing factor of this serious adverse effect [106]. The effect of different routes of administration of corticosteroids on elevation of IOP will be discussed later in more detail [105].

Furthermore, topically applied corticosteroids are unlikely to attain therapeutic drug concentrations in the back of the eye and are therefore not the best option for treatment of vitreoretinal conditions [106, 107]. Nonetheless, corticosteroid difluprednate ophthalmic drops have been suggested as candidates for reducing macular oedema in children [108]. Most recently, we have reported that topically administered beclomethasone dipropionate loaded cubosomes markedly improve the endotoxininduced uveitis in the rabbit model. Results also proved that the lipophilic beclomethasone dipropionate penetrated ocular tissue and significantly reduced inflammation induced in the retina [109].

The intraocular anti-inflammatory effect of a topically applied corticosteroid not only depends on its potency but also on its metabolic stability and elimination and its ability to penetrate multiple physiological barriers [110]. Various advanced ophthalmic formulations for corticosteroids including nanosuspension, nanoemulsions, microemulsions [43], liposomes [111], niosomes [50] and cubosomes [39, 112] have been developed to overcome the limitations of conventional solutions and suspensions of corticosteroids. These novel formulations could serve as potential alternatives for conventional ophthalmic pharmaceuticals. This is because of their improved ocular availability and/or tolerability as they provide controlled or sustained drug release [106]. For example, topical administration of prednisolone acetate 1\% microsuspension increased the intraocular concentration of prednisolone acetate up to 20fold. Li Gan et al [39] reported that the $\mathrm{P}_{\text {app }}$ values were $2.16 \times 10^{-6}$ and $0.48 \times 10^{-6} \mathrm{~cm} / \mathrm{s}$ 
for dexamethasone-cubosomes and dexamethasone-Na phosphate eye drops, respectively. These results indicated a 4.5 -fold increases in dexamethasone corneal penetration with cubosomes [39]. Moreover, the ocular bioavailability of prednisolone acetate and prednisolone sodium phosphate loaded into nano-sized ethoniosomes was 1.54- and 1.75-fold higher than that for the conventional suspension and solution eye drops containing prednisolone acetate and prednisolone sodium phosphate, respectively $[50]$.

Table 2 shows more examples of lipid-/surfactant-based vesicles that markedly improved ocular bioavailability and apparent permeability coefficient $\left(\mathrm{P}_{\text {app }}\right)$ of corticosteroids such as dexamethasone and prednisolone. These results demonstrated the beneficial role of the lipid-based nanosized systems, including, niosomes, ethoniosomes, liposomes and cubosomes in enhancing corneal delivery of corticosteroids compared with the conventional dosage form. These novel delivery systems may increase ocular bioavailability, prolong drug action, and decrease side effects in the anterior eye with enhanced ocular biocompatibility and tolerability [39, 113].

However, the therapeutic effect of topically applied corticosteroids requires penetration of the applied drug through the ocular surface barriers including precorneal tear film, cornea, and/or conjunctiva/sclera. The cornea, which represents the greatest barrier for intraocular penetration, has lipophilic and hydrophilic regions, requiring drugs with an optimal $\log \mathrm{P}$ or lipophilicity-hydrophilicity balance [114]. The cornea is less permeable to more polar and hydrophilic corticosteroids such as sodium salts of corticosteroid phosphate $[115,116]$ compared to the alcoholic and acetate derivatives of dexamethasone and prednisolone that are more lipophilic [117, 118].

The concentration of prednisolone was determined in human aqueous humor after topical administration of $50 \mu 1$ of prednisolone acetate $(1 \%)$ and prednisolone sodium phosphate $(0.5 \%)$. Unsurprisingly, the mean peak concentration of prednisolone in aqueous humor after two hours of the topical application was $669 \mathrm{ng} / \mathrm{ml}$ and $25.6 \mathrm{ng} / \mathrm{ml}$ for prednisolone acetate and prednisolone sodium phosphate, respectively. These results reflected a 26-fold higher corneal penetration of the lipophilic prednisolone acetate compared to the polar prednisolone phosphate [119]. 
The addition of cyclodextrins resulted in enhancement of both solubility, corneal permeability and ocular bioavailability of dexamethasone compared with commercially available dexamethasone alcohol $(0.1 \%)$ solution [120]. However, the enhanced corticosteroid ocular bioavailability can result in a significant elevation of IOP and increased sensitivity to eye infections, such as those caused by herpes simplex virus $[16,121]$.

Table 2 Lipid-based systems for ocular delivery of selected corticosteroids and their effects on ocular pharmacokinetics.

\begin{tabular}{|c|c|c|c|}
\hline $\begin{array}{l}\text { Lipid-based } \\
\text { delivery system }\end{array}$ & $\begin{array}{l}\text { Loaded } \\
\text { corticosteroids }\end{array}$ & Ocular pharmacokinetics & Reference \\
\hline Cubosomes & $\begin{array}{l}\text { Beclomethasone } \\
\text { dipropionate }\end{array}$ & $\begin{array}{l}\text { Cubosomes increased the } \mathrm{P}_{\text {app }} \text { by } 3.8 \text {-fold compared to the } \\
\text { control suspension. The precorneal residence time and the } \\
\text { AUC increased by } 8.5 \text { - and } 5.5 \text {-fold, respectively, compared } \\
\text { to the control sodium fluorescein solution. The ocular } \\
\text { bioavailability of the loaded drug was } 5.52 \text { compared to the } \\
\text { suspension form. }\end{array}$ & [109] \\
\hline Cubosomes & Dexamethasone & $\begin{array}{l}\text { Cubosomes increased the } \mathrm{P}_{\text {app }} \text { and the AUC by } 4.5 \text { - and } 1.8 \text { - } \\
\text { fold compared to suspension eye drops. }\end{array}$ & [39] \\
\hline Ethoniosomes & $\begin{array}{l}\text { Prednisolone } \\
\text { acetate }\end{array}$ & $\begin{array}{l}\text { Ethoniosomes enhanced the ocular bioavailability (AUC) by } \\
1.54 \text {-fold compared to the commercial suspension eye drops. }\end{array}$ & {$[50]$} \\
\hline Liposomes & $\begin{array}{l}\text { Dexamethasone } \\
\text { hemisuccinate }\end{array}$ & $\begin{array}{l}\text { Liposomes showed 2.3-time reduction in the pro- } \\
\text { inflammatory cytokine interleukin } 6 \text { (IL-6) concentration } \\
\text { compared with the free dexamethasone hemisuccinate } \\
\text { solution. }\end{array}$ & [122] \\
\hline Liposomes & $\begin{array}{l}\text { Prednisolone } \\
\text { acetate }\end{array}$ & $\begin{array}{l}\text { Liposomes increased the AUC compared to control solution. } \\
\text { Also, they markedly reduced the inflammatory signs of } \\
\text { uveitis compared to the solution dosage form, indicating } \\
\text { enhanced ocular bioavailability. }\end{array}$ & [123] \\
\hline $\begin{array}{c}\text { Niosomes in situ- } \\
\text { gel }\end{array}$ & $\begin{array}{l}\text { Prednisolone } \\
\text { sodium phosphate }\end{array}$ & $\begin{array}{l}\text { Niosomal in situ-gel increased AUC and } \mathrm{P}_{\text {app }} \text {, value by } 1.75 \text { - } \\
\text { and } 2.82 \text {-fold, respectively, compared to the control pure drug } \\
\text { solution. } \\
\text { The } \mathrm{T}_{\max } \text { increased from } 1 \mathrm{~h} \text { for solution to } 2 \mathrm{~h} \text { for the } \\
\text { niosomal in situ-gel. }\end{array}$ & {$[124]$} \\
\hline
\end{tabular}




\subsection{Systemic administration}

The systemic administration of corticosteroids had been widely used in ocular clinical practice for controlling ocular inflammatory disorders since the 1950s [125]. It has been indicated as a potential alternative to the topical application for the treatment of diseases of the posterior segment of the eye $[126,127]$. Systemic corticosteroids, especially oral corticosteroids, may show higher patient compliance. However, the blood-retinal barrier and blood-aqueous barrier remain could hinder drug access into the posterior and anterior segments $[128,129]$. As such, ocular bioavailability following systemic administration of corticosteroids is low, thus, higher dose administration is needed $[130,131]$. As a result, severe ocular side effects could be triggered including steroidinduced IOP elevation, cataract formation, and recurrence of herpes simplex infection $[16,132,133]$. In addition, it may lead to serious acute and chronic systemic side effects throughout the body including osteoporosis [134, 135], immunosuppression, Cushing's syndrome [136, 137], adrenal suppression [138] and elevated blood pressure $[132,139]$.

It has been reported that a single intravenous injection of prednisolone $(500 \mathrm{mg})$ resulted in $50 \%$ of the steroidal concentration in the aqueous humor produced by topical administration of four drops of methylprednisolone $0.5 \%$ eye drop $[88,140]$.

Also, Hyndiuk et al. [141] demonstrated that the systemic administration (via the intramuscular route) of methylprednisolone in monkeys resulted (at two days after injection) in ocular corticosteroid concentration that was less than $1 \%$ of what was achieved by periocular injection of an equal dose [141]. These findings further indicate the limited ocular bioavailability of systemically administered corticosteroids.

The transport of drugs across the blood-ocular barrier is controlled by drug characteristics where it is more permeable to lipophilic substances with high oil/water partition coefficients [142]. Radiographic localization study of dexamethasone following systemic administration revealed that it penetrated the choroid, retina and sclera, which may be attributed to its lipophilic nature [143-145]. Interestingly, systemic corticosteroids have been approved for treatment of various ophthalmic conditions. For instance, oral prednisolone is approved for ocular adnexal IgG4-related disease [146]. The intravenous methylprednisolone administration has been recommended in case of severe uveitis when rapid control of the inflammation is required [147]. Keratoplasty (corneal transplant) rejections and chronic bilateral uveitis 
are better treated with systemic corticosteroids (prednisolone $1 \mathrm{mg} / \mathrm{kg} / \mathrm{day}$ ) than other routes of administration [148].

\subsection{Periocular injection}

Periocular refers to the area that surrounds the eye globe and the periocular route provides local drug delivery to spaces directly surrounding the eye, adjacent to the sclera [149]. The injected drug crosses the sclera through passive diffusion and hence, the molecular weight of the administered drug is the rate-limiting step [150]. The Periocular injections include drug administration via the subconjunctival, sub-Tenon, peribulbar, and retrobulbar regions (Figure 3) [151]. For posterior eye diseases, especially for diseases affecting the outer ocular layers, periocular administration has been considered as a useful route [152]. Owing to the porous nature and the huge scleral surface area $\left(16.3 \mathrm{~cm}^{2}\right)$, the periocular route can deliver substances with high molecular weight to the posterior segment of the eye [153]. Studies have reported that the relatively porous scleral membrane, compared to cornea, is permeable to larger molecules such as therapeutic proteins up to $150 \mathrm{KDa}$ molecular weight $[154,155]$. Therefore, the transscleral periocular drug delivery provides an option for delivery of large hydrophilic molecules which is facilitated by the increased surface area and high permeability of the sclera relative to cornea [152].

The lipophilicity of drug molecules can also influence their scleral permeation Studies looking at the correlation between drug lipophilicity and human scleral permeation showed that molecules with higher lipophilicity exhibited stronger binding to the sclera and thus, a longer transport time across the tissue [156].

Additionally, this route is commonly used for anesthesia before ocular surgery [152]. Depending on the drug characteristics, the administered drug can reach the vitreous and other intraocular tissues within 20-30 minutes following administration [157]. While periocular administration is considered to be less invasive than intravitreal injection, periocular corticosteroid administration has complications including elevation of IOP, cataract formation and corneal decompensation [158, 159]. Also, it has been accompanied by atrophy of the orbital rim fat [160].

\subsubsection{Subconjunctival injection}


When administered via the subconjunctival route, the drug is placed below the conjunctiva, where it penetrates directly, by diffusion, through the sclera, bypassing the conjunctival barrier which limits the bioavailability of topically instilled drugs (Figure 3) [92]. Through the subconjunctival route, up to $500 \mu 1$ could be injected and the drug substance could be delivered to both the posterior and anterior segments. Experimental evidence on dexamethasone revealed that the concentration after subconjunctival injection was 12 times more than that of oral administration [161, 162].

Kompella et al. [163] successfully prepared budesonide loaded polylactide (PLA) nano and microparticles. After subconjunctival injection in a rat model, this system effectively sustains the concentration of budesonide in the retina compared to a solution form. In rats treated with budesonide-loaded PLA nanoparticles, the retinal concentration of budesonide was nine-fold higher compared with the group treated with budesonide solution. Additionally, this study showed that budesonide decreases VEGF expression in retinal pigment epithelial cells via the glucocorticoid receptor activity [163]. Weijtens et al. [161] measured the concentration of dexamethasone in the human subretinal fluid after an oral dose of $7.5 \mathrm{mg}$ dexamethasone and subconjunctival injection of $2.5 \mathrm{mg}$ of dexamethasone sodium phosphate. The findings revealed a 28.7fold higher concentration of dexamethasone in the subretinal fluid following the subconjunctival injection compared to the oral administration [161].

However, the subconjunctival corticosteroid injection may be less effective than topical administration in the treatment of inflammation of the ocular surface [164]. After subconjunctival injection $\mathrm{s}$, most of the injected corticosteroid is believed to leak back to the ocular surface through the needle tract reducing the injected drug depot $[165$, 166]. Additionally, some of the injected drugs are systemically absorbed via the conjunctival and episcleral blood supply, which may affect the ocular surface bioavailability of subconjunctivally injected drugs $[162,167]$. The local depot effect of injected corticosteroids makes them potentially helpful in prolonging the release of effective concentrations to the cornea, conjunctiva, sclera, choroid and retina [168]. Generally, parenteral corticosteroid solutions are well tolerated when injected subconjunctivally [169].

The effect of the subconjunctivally injected suspensions of dexamethasone $(1 \mathrm{mg})$ is believed to last for 1 to 2 days. However, triamcinolone acetonide ( $3 \mathrm{mg}$ ) lasted for up to 21 days. This can be attributed to the more inherent sustained release characteristics 
(slower dissolution rate) of triamcinolone acetonide due to it being more lipophilic and less water soluble than dexamethasone (Table 1) [169]. The subconjunctival injections were associated with some ocular side effects such as ocular pain, retinal detachment, globe perforation [170] and formation of granuloma at the injection site [159, 171].

\subsubsection{Sub-Tenon injection}

The sub-Tenon injection involves drug injection into the sub-Tenon's space (the space located between the sclera and the capsule) (Figure 3) [107, 172]. Sub-Tenon corticosteroid injections have been used for the treatment of various ocular inflammatory conditions. It is most commonly used for local administration of anesthesia during ocular surgery. This route is also used for corticosteroid delivery to the posterior segment of the eye [152].

The sub-Tenon injection of triamcinolone acetonide has been effectively used in the treatment of patients with macular edema and posterior uveitis. In one study, an increase in the IOP was observed in $2.17 \%$ of 507 treated eyes [173, 174]. Cardillo et al. [175] compared the efficacy of sub-Tenon injection of triamcinolone acetonide with that of the intravitreal injection in the treatment of macular oedema in human eyes. After a 1month follow up, they revealed that the intravitreally injected triamcinolone acetonide (4-mg) significantly decreased the macular thickness, which was greater than that produced by sub-Tenon injection of triamcinolone acetonide (40-mg) [175].

In another study, the posterior sub-Tenon injection of triamcinolone acetonide was used for macular edema treatment in patients with average macular thickness above $300 \mu \mathrm{m}$ and who did not respond to intravitreal injection of the anti-VEGF bevacizumab. The sub-Tenon injection of triamcinolone acetonide $(20 \mathrm{mg})$ was found to effectively inhibit VEGF and reduce the average macular thickness from $476 \mu \mathrm{m}$ to $368 \mu \mathrm{m}$ after 2months treatment. No serious complications were reported [176].

\subsubsection{Retrobulbar injection}

Retrobulbar injection involves the injection of the drug into the conical section within the borders of the rectus muscles and their intramuscular septa and the drug injected within the muscle cone behind the globe of the eye (Figure 3) [177]. Retrobulbar 
injection is advocated for posterior segment drug delivery to attain high drug concentration in the posterior tissue and avoid the systemic toxicity. This route is commonly used for anesthesia during ocular surgery where up to $5 \mathrm{ml}$ could be injected [151]. For corticosteroid administration, the systemic and retrobulbar injection of 0.3 $\mathrm{ml}$ suspension of tritiated 6-methyl-prednisolone acetate in monkey showed a higher drug concentration in the posterior tissue (retina) after two days (drug persisted for nine days when assayed) following retrobulbar administration. However, no drug was detected on days 2 and 9 after intramuscular injection. This indicated that corticosteroids could penetrate and last longer in monkey ocular tissue after retrobulbar injection compared with systemic intramuscular injection [141]. However, this route of ocular injection increases the risk of optic nerve trauma; consequently, the needle should not penetrate further than $1.5 \mathrm{~cm}$ behind the globe [151].

\subsubsection{Peribulbar injection}

Unlike the retrobulbar injection, for peribulbar injection, the muscle cone is not involved and the drug is injected externally to the rectus muscles and their intramuscular septa (Figure 3) [178]. Up to $10 \mathrm{ml}$ of drug formulation could be injected through peribulbar route depending on patient comfort and the speed of injection [151]. Anesthesia through the peribulbar injection is considered less effective than the retrobulbar route but is still used in case of complicated ocular surgery [152]. However, globe perforation is a risk, commonly associated with peribulbar injection where special care should be taken to ensure the needle is in the correct position [151]. Furthermore, this route is more likely to elevate IOP compared with the retrobulbar injection [152]. Despite the benefits of periocular corticosteroid administration, there is a high risk of development of systemic adverse effects, hemorrhage, hyperemia and the possibility of conjunctival irritation in addition to patient compliance challenges [23, $151]$.

\subsection{Intraocular injection}

Intraocular injection involves direct localization of corticosteroids intraocularly, bypassing ocular barriers related to both topical and systemic administration (Figure 3). Although intraocular injections are more helpful for local treatment of several ocular 
diseases, there are many potential complications that are divided into corticosteroidand injection-related unwanted effects. The most common corticosteroid-related side effects are cataract, IOP elevation, increased infection potential and reduced wound healing [179, 180]. Injection-related adverse effects include pain, increased risk of globe perforation, vitreous hemorrhage, retinal detachment, bacterial endophthalmitis, and non-infectious endophthalmitis [181-183]. Intraocular injections in the clinic or developmental stages include intracameral, intravitreal and suprachoroidal injections.

\subsubsection{Suprachoroidal injection}

A recent approach to overcome the ocular barriers related to topical administration and target the posterior eye segment is via drug administration to the suprachoroidal space (SCS) [184]. This localized ocular drug delivery approach allows targeted delivery to the choroid and retina, away from the anterior segment (Figure 3) [185, 186].

SCS drug administration is currently undergoing late-stage clinical evaluation. It is anticipated that a well-developed formulation injected into the SCS spreads quickly, exposing the drug to a wide region of the choroid-retina interface, thereby allowing drug transit into the choroid and the retinal layers [187]. However, this injection site allows a rather limited volume $(200 \mu \mathrm{l})$ to be injected and if the injected volume is exceeded, it might lead to choroidal edema or choroidal detachment $[188,189]$. Drugs injected in the SCS preferentially target tissues of the back of the eye, relative to the anterior chamber, cornea or conjunctiva. Therefore, a decrease in corticosteroid associated adverse effects, such as IOP elevation and cataract formation can be anticipated, [188]. XIPERETM is triamcinolone acetonide suspension intended for suprachoroidal injection and is currently under marketing approval and commercialization in USA, UK and Australasia for treatment of macular edema associated with uveitis [190].

In the rabbit model, the suprachoroidal injection of triamcinolone acetonide suspension resulted in high triamcinolone acetonide concentrations in sclera, choroid, and retina. However, it was not detected in the aqueous humor [191]. This unique drug distribution may reduce the corticosteroid-induced ocular side effect [192]. A human clinical study was performed by Goldstein et al. [192] in the USA. They elucidated that a single suprachoroidal injection of triamcinolone acetonide was tolerable for the treatment of 
noninfectious uveitis. Only ocular pain at the time of injection was noted, with no IOP elevation or systemic side effects [192].

Currently, clinical trials are underway for dosing SCS using microneedles. These provided a minimally invasive approach for drug delivery and did not result in hemorrhage and retinal detachment [193, 194]. Moreover, the actual site of injection completely sealed an hour after injection [194]. Gilger et al. [195] studied the effect of triamcinolone acetonide injected into the SCS by a microneedle and compared it with that injected intravitreally when treating endotoxin-induced posterior inflammation in a porcine eye model. The animals with the induced inflammation were treated by suprachoroidal injection of $0.2 \mathrm{mg}$ of triamcinolone acetonide and intravitreal injection of $2.0 \mathrm{mg}$ of Triesence ${ }^{\circledR}$ (a commercially available triamcinolone acetonide). Triamcinolone acetonide was diluted using a vehicle to provide $(0.2 \mathrm{mg} / 100 \mu \mathrm{L})$ for suprachoroidal injection and $(2.0 \mathrm{mg} / 100 \mu \mathrm{L})$ for intravitreal injection. They indicated that microneedle injection of triamcinolone acetonide is simple, effective, with a lower risk of infection or mechanical retinal damage relative to intravitreal injection [195]. They also revealed that suprachoroidal and intravitreal administration were equally effective in improving the endotoxin-induced uveitis in the porcine model. In addition, no elevation of IOP was observed after microneedle SCS injection of triamcinolone acetonide. This indicated at least a 10-fold reduction in the effective dose of TA when administered through suprachoroidal injection due to targeted triamcinolone acetonide delivery [195].

\subsubsection{Intracameral route}

Intracameral injection involves the local injection of drug substances into ocular cavities, bypassing the corneal barrier (Figure 3). It may be used to deliver antibiotics and corticosteroids directly to the aqueous humor [196]. This route of ocular drug delivery provides direct drug delivery to the anterior chamber, hence, less of the drug is needed to achieve the desired effect with reduced side effects relative to topical and systemic drug administration [197].

Tan et al. [198] studied the efficacy of intracameral injection of dexamethasone (Surodex ${ }^{\circledR} 60 \mu \mathrm{g}$ ) and topical dexamethasone administration ( $0.1 \%$ dexamethasone eye drops) for postoperative ocular inflammation after cataract surgery. On day 14 of 
treatment, the inflammation assessment showed lower flare and cell values with intracameral Surodex ${ }^{\circledR}$ treated group compared to those treated by topical dexamethasone eye drops [198].

Dexamethasone, injected intracamerally for controlling postoperative inflammation after cataract surgery, provided a higher drug level with lower side effects including IOP elevation compared to those resulting from topical or systemic administration [197]. This is attributed to the localized low dose administration achieved by intracameral injection compared with topical and systemic administrations.

The efficacy of intracameral injection of triamcinolone acetonide was studied by Wang et al. [199] in a prospective randomized controlled trial. They observed that intracameral injection of triamcinolone acetonide effectively reduces the aqueous inflammation and improves the visual acuity after phacotrabeculectomy [199]. Simaroj et al. [200] revealed that a single intracameral injection of triamcinolone acetonide (2 $\mathrm{mg}$ in $0.1 \mathrm{ml})$ in combination with gentamycin $(0.2 \mathrm{mg}$ in $0.1 \mathrm{ml})$ could be used as an effective treatment of ocular inflammation following cataract surgery. No serious side effects or elevation in the IOP were reported one month following injection [200].

However, there are certain adverse effects related to the intracameral route of ocular drug delivery, especially with sustained-release implants. These include tissue hemorrhage, prolapse of the iris, surgical hyphema and possibility of implant migration [197]. Also, there is an increased risk of toxic anterior segment syndrome with intravitreal injections, which involves postoperative inflammatory response as a result of the injection of noninfectious substances into the anterior chamber [197, 201]. Despite such limitations, an intracamerally injected biodegradable implant for sustained reduction of intraocular pressure in patients with open angle glaucoma or ocular hypertension has been approved by the US FDA during 2020, suggesting adequate riskbenefit ratio.

\subsubsection{Intravitreal route}

Intravitreal injections of corticosteroids have been progressively used instead of systemic administration for the treatment of a number of diseases that affect the posterior segment of the eye including macular edema and noninfectious posterior uveitis. Unlike systemic administration, which requires milligram doses each day, a 
sub-milligram dose of corticosteroid is sufficient in slow-release systems administered intravitreally over durations of 0.5 to 3 years. This is because the intravitreal injection bypasses the blood-ocular barrier and other barriers related to topical administration by direct localization of the drug in the vitreous, thereby achieving therapeutic levels in the eye, minimizing both drug dose needed as well as systemic adverse effects (Figure 3) [202]. The maximum volume injected intravitreally is limited to $100 \mu 1$ [203] and half-life in the vitreous is a few hours. Consequently, repeated monthly injections, sometimes life long, are required for sustained drug effects and improving therapeutic outcomes [203]. A key goal of drug delivery research is to prolong vitreal residence time of drugs using different drug forms or slow release systems since repeated intraocular injections increase the risk of injury and infection to the eye.

Vitreal half-life of drugs depends on drug lipophilicity, solubility, and molecular weight. Smaller molecules can be distributed and cleared more rapidly than larger ones [204]. Further, the vitreal half-life generally increases with an increase in drug hydrophilicity and molecular weight [205]. Injection of drug suspensions as opposed to a solution form of the drug is one approach to prolong the apparent vitreal half-life from a few hours to several days. Durairaj et al. [205], proposed dose number as the ratio of the drug dose to vitreal solubility, with a half-life of drug suspensions increasing as the dose number increases. This study also indicated that the presence of pigment in the eye increases the half-life of a drug molecule. Relationship between vitreal half-life and dose number is evident in the greater persistence of triamcinolone acetonide as the drug dose is increased. When triamcinolone acetonide dose was increased from 4 to $24 \mathrm{mg}$, the drug was present in the aqueous humor at 6 months post-dosing. This could be due to inefficient dissolution or dose-limited dissolution of triamcinolone acetonide in the vitreous humor [206]. Thus, drug solubility is a critical factor in increasing the mean residence time in the vitreous humor, with the apparent half-life increasing with a decrease in drug solubility or dose in the vitreous humor. The water-soluble dexamethasone sodium phosphate was found to have a shorter half-life (about three hours) within the vitreous humor, while the more lipophilic corticosteroid triamcinolone acetonide showed a longer residence time up to a few months [207, 208]. Triamcinolone acetonide, which is a synthetic corticosteroid that was formulated as an injectable suspension, can last in the vitreous for a much longer time than some others due to its lower water solubility [209]. 
Commercially approved intraocular triamcinolone suspensions include Triesence ${ }^{\circledR}$ and Trivaris $^{\circledR}$ [30]. Triesence ${ }^{\circledR}$ (aqueous suspension) provides $40 \mathrm{mg} / \mathrm{mL}$ of TA and the vehicle is free from preservatives [210]. Trivaris ${ }^{\circledR}$ contains $80 \mathrm{mg} / \mathrm{mL}$ of TA in a hydrogel (HYLADUR) in a preservative-free vehicle [211]. These suspensions were approved for the treatment of ocular inflammation that do not respond to topical corticosteroid administration [30]. Interestingly, both Triesence ${ }^{\circledR}$ and Trivaris ${ }^{\circledR}$ prolonged corticosteroid activity mainly based on their inherent lipophilicity and low solubility rather than the excipients or polymers used in the formulations [212].

Vitreal half-life also depends on the health of the vitreous humor. Beer et al. [206] studied the pharmacokinetics of triamcinolone acetonide after intravitreal injection of $4 \mathrm{mg}$ dose in vitrectomized and non-vitrectomized human eyes. They revealed that the elimination half-life was 18.6 days and 3.2 days in non-vitrectomized and vitrectomized eyes, respectively. Thus, the health of the vitreous humor is expected to play a role in drug disposition.

Since a key goal of ocular corticosteroid therapy is to maximize the efficacy and to minimize the well-known adverse effects induced by corticosteroids and also to avoid the related systemic adverse effects, minimizing the exposure of the trabecular meshwork to corticosteroids by using low dose and posterior positioning of an intraocular implant could reduce the corticosteroid-induced local side effects, while simultaneously reducing the risk of systemic side effects $[30,213]$. There are a number of corticosteroid implants with long-acting and slow-release properties that offer several advantages over topical and systemic administration. This is because the corticosteroids intraocular implants can bypass the blood-ocular barriers, require ultralow doses and avoid adverse effects associated with the systemic therapy.

The implants reduce the risk associated with repeated intraocular injections. This would be of great benefit in the case of drugs that may be highly toxic when administered systemically [214]. Three common members (dexamethasone, fluocinolone acetonide and triamcinolone acetonide) of the corticosteroid family with different structures and pharmacokinetic properties has gained regulatory approval as intraocular implants for various ocular inflammatory conditions (Table 3). 
Dexamethasone is relatively less potent and more water-soluble $(0.16 \mathrm{mg} / \mathrm{ml})[38]$ than both triamcinolone acetonide $(21 \mu \mathrm{g} / \mathrm{ml})$ [59] and fluocinolone acetonide $(0.05 \mathrm{mg} / \mathrm{ml})$ [64].

Dexamethasone is formulated in a slow-release implantable delivery system in order to sustain therapeutic doses in the eye and commercially known as the intravitreal implant Ozurdex ${ }^{\circledR}$ [6]. Ozurdex ${ }^{\circledR}$ is the first commercially available implantable device of dexamethasone which was approved by the FDA in 2009 for the treatment of macular edema [6]. It contains dexamethasone which is incorporated into a biodegradable polymer, poly(lactic-co-glycolic) acid (PLGA). Ozurdex ${ }^{\circledR}$ was implanted intravitreally under sterile conditions for slow release of dexamethasone over 6 months into vitreous and diffuse into the target tissue of the choroid for treatment of uveitis [28].

Pharmacokinetics of intravitreally injected Ozurdex ${ }^{\circledR}$ were studied in an animal model. Following bilateral Ozurdex ${ }^{\circledR}$ implantation in 34 male monkeys, the results showed a higher rate of initial drug release during the first two months followed by a prolonged low level of release and dexamethasone level was below the limit of detection after 6 months [215]. A more recently approved dexamethasone-based slow release system is $\mathrm{DEXYCU}^{\circledR}$. It was approved in 2018 for postoperative inflammation treatment and is based on an injectable sustained and bioerodible ocular delivery system (verisome ${ }^{\mathrm{TM}}$ ) [216]. DEXYCU ${ }^{\circledR} 9 \%$ intraocular suspension is dexamethasone suspension which is intracamerally injected as a single dose $(50 \mu \mathrm{l})$. The injected DEXYCU ${ }^{\circledR}$ has the ability to transform into small spheres at the injection site and these spheres are gradually degraded to release dexamethasone for up to 3 weeks for treatment of post-operative inflammation after cataract surgeries [216, 217]

Fluocinolone acetonide is a more potent corticosteroid with slightly higher water solubility compared to triamcinolone acetonide. Fluocinolone acetonide has three approved intravitreal implants: Retisert ${ }^{\circledR}$ and Iluvien ${ }^{\circledR}$ and Yutiq ${ }^{\circledR}$. Retisert ${ }^{\circledR}$ [218] has the fluocinolone acetonide surrounded by a polyvinyl acetate/silicone thin layer fixed onto a structural base.

Fluocinolone acetonide was approved by FDA in 2005. It is implanted surgically into the posterior segment of the eye for chronic noninfectious uveitis treatment. Pharmacokinetic studies showed a near zero-order drug delivery. The vitreous concentration was relatively constant following 2 hours implantation and lasted for one 
year after vitreous implantation also the fluocinolone acetonide plasma level was under the detection limit at all times [219].

Iluvien ${ }^{\circledR}$ is the only fluocinolone acetonide implant that has been approved by the FDA since September 2014 for the treatment of DME [220]. Similarly, a near zero-order release was observed following the intravitreal injection of Iluvien ${ }^{\circledR}$ [221]. Moreover, after fluocinolone acetonide intravitreal implantation in patients having DME, the loaded drug was found to be released in a sustained manner into the aqueous and vitreous humor over 3 years. The steady-state fluocinolone acetonide aqueous concentration was in the range of $0.5-1.0 \mathrm{ng} / \mathrm{ml}$ for $6-9$ months and the concentrations were constant between 1-3 year where the mean peak concentration was about 0.6 $\mathrm{ng} / \mathrm{ml}$ at 3 years with detectable fluocinolone acetonide aqueous concentration up to 3 years [222]. Unfortunately, patients receiving fluocinolone acetonide implants were found to be at higher risk of developing elevated IOP [223]. Interestingly, during late 2018, the FDA approved YUTIQ ${ }^{\mathrm{TM}}$ (non-bioerodible intravitreal micro-insert) for sustained delivery of fluocinolone acetonide $(0.18 \mathrm{mg})$ with linear sustained release kinetics up to 3 years for the treatment of chronic non-infectious uveitis [224].

After intravitreal drug injection, elimination of the injected drug can occur through the anterior route via the aqueous humor turnover or through the posterior route via penetration of the retina and vascular barriers in the back of the eye [92, 225]. Literature reports indicate that diabetic retinopathy can be improved by intravitreal injection of dexamethasone in animal models [226]. This is probably due to the lipophilic nature of dexamethasone and ready access of the drug to the retinal tissue.

For intravitreally injected nanoparticles, the surface charge influences their vitreous mobility. Peeters et al. [227] reported that the intravitreally injected polystyrene nanospheres showed restricted mobility in the vitreous as a result of their adherence to the collagen fibers. However, the attachment of polyethylene glycol to their surfaces prevented their adherence to $t$ collagen and consequently allowed improved particle movement in the vitreous [227].

The complications of intravitreal corticosteroids injection are commonly divided into two main groups firstly, corticosteroids-related side effects such as elevated IOP and cataract formation. Secondly, side effects related to injection such as vitreous 
hemorrhage, detachment of the retina, infectious endophthalmitis and non-infectious endophthalmitis [197, 228].

Studies of intraocular implants revealed that corticosteroid-induced IOP elevation was lower in the dexamethasone implant group, compared to the patients treated with fluocinolone acetonide and or triamcinolone acetonide implants. Corticosteroidinduced IOP elevation was observed in $11 \%$ of individuals following intravitreal implantation of $0.35 \mathrm{mg}$ of dexamethasone. However, 32 and $66 \%$ of individuals developed elevated IOP after intravitreal implantation of $4 \mathrm{mg}$ triamcinolone acetonide and $0.59 \mathrm{mg}$ of fluocinolone acetonide, respectively [65]. This may be due to the lipophilicity of dexamethasone, which is lower than that of triamcinolone acetonide and fluocinolone acetonide, resulting in less binding to the ocular tissues of the trabecular meshwork and the human lens reducing the risk of elevation of IOP and cataract development [229]. Nevertheless, intraocular implants have local side effects (Table 3) such as conjunctival hemorrhages, retinal tears, retinal detachment and endophthalmitis [230].

Table 3 Corticosteroid implants and suspensions approved for intravitreal injection

\begin{tabular}{|c|c|c|c|c|c|c|c|}
\hline $\begin{array}{c}\text { Corticosteroid } \\
\text { member }\end{array}$ & Dosage form & $\begin{array}{c}\text { Route of } \\
\text { administrati } \\
\text { on }\end{array}$ & Clinical uses & $\begin{array}{c}\text { Main } \\
\text { advantages }\end{array}$ & $\begin{array}{l}\text { Major }(>10 \%) \\
\text { adverse effects }\end{array}$ & $\begin{array}{c}\text { Duration } \\
\text { of } \\
\text { Therapy }\end{array}$ & References \\
\hline Dexamethasone & $\begin{array}{c}\text { Ozurdex }{ }^{\circledR} \\
(0.7 \mathrm{mg}) \\
\text { (biodegradable } \\
\text { implant) }\end{array}$ & $\begin{array}{c}\text { Intravitreal } \\
\text { implant }\end{array}$ & $\begin{array}{c}\text { Macular edema } \\
\text { Following } \\
\text { BRVO or } \\
\text { CRVO } \\
\text { Posterior } \\
\text { segment uveitis }\end{array}$ & $\begin{array}{l}\text { Long-acting } \\
\text { device with } \\
\text { less repeated } \\
\text { intravitreal } \\
\text { injections }\end{array}$ & $\begin{array}{c}\text { Elevated IOP }(25 \%) \\
\text { Conjunctival } \\
\text { hemorrhage }(22 \%)\end{array}$ & $\begin{array}{l}\text { Up to } 6 \\
\text { months }\end{array}$ & {$[28,40]$} \\
\hline
\end{tabular}




\begin{tabular}{|c|c|c|c|c|c|c|c|}
\hline $\begin{array}{l}\text { Fluocinolone } \\
\text { acetonide }\end{array}$ & $\begin{array}{c}\text { Retisert }{ }^{\circledR} \\
(0.59 \mathrm{mg}) \\
\text { (non- } \\
\text { biodegradable) } \\
\text { implant }\end{array}$ & $\begin{array}{l}\text { Implanted } \\
\text { surgically into } \\
\text { the posterior } \\
\text { segment of } \\
\text { the eye }\end{array}$ & $\begin{array}{l}\text { Chronic non- } \\
\text { infectious } \\
\text { uveitis }\end{array}$ & $\begin{array}{l}\text { Much longer } \\
\text { therapy than } \\
\text { Ozurdex }{ }^{\circledR}\end{array}$ & $\begin{array}{c}\text { Elevation of IOP } \\
\text { Cataract } \\
\text { Ocular pain }\end{array}$ & $\begin{array}{l}\text { Up to } 30 \\
\text { months }\end{array}$ & [66] \\
\hline $\begin{array}{l}\text { Fluocinolone } \\
\text { acetonide }\end{array}$ & $\begin{array}{c}\text { Iluvien }{ }^{\circledR} \\
(0.19 \mathrm{mg}) \\
\text { (non- } \\
\text { biodegradable) } \\
\text { implant }\end{array}$ & $\begin{array}{c}\text { Intravitreal } \\
\text { implant } \\
\text { (injected } \\
\text { using a 25- } \\
\text { gauge needle } \\
\text { into vitreous) }\end{array}$ & $\begin{array}{c}\text { Diabetic } \\
\text { macular edema }\end{array}$ & $\begin{array}{l}\text { Does not } \\
\text { require } \\
\text { sutures }\end{array}$ & $\begin{array}{c}\text { Cataract }(82 \%) \\
\text { Myodesopsia }(21 \%) \\
\text { Conjunctival } \\
\text { hemorrhages }(13 \%)\end{array}$ & $\begin{array}{l}\text { Up to } 36 \\
\text { months }\end{array}$ & {$[221,231]$} \\
\hline $\begin{array}{c}\text { Triamcinolone } \\
\text { acetonide }\end{array}$ & $\begin{array}{c}\text { Triesence }{ }^{\circledR} 40 \\
\mathrm{mg} / \mathrm{ml} \\
\text { Trivaris }{ }^{\circledR} 80 \\
\mathrm{mg} / \mathrm{ml}\end{array}$ & $\begin{array}{c}\text { Intravitreal } \\
\text { injection }(25- \\
100 \mu 1 \text { per } \\
\text { single } \\
\text { injection })\end{array}$ & $\begin{array}{c}\text { Uveitis } \\
\text { Temporal } \\
\text { arteritis } \\
\text { Ocular } \\
\text { inflammatory } \\
\text { conditions }\end{array}$ & $\begin{array}{c}\text { Simple } \\
\text { needle } \\
\text { injection, less } \\
\text { expensive } \\
\text { and does not } \\
\text { require } \\
\text { surgical } \\
\text { placement }\end{array}$ & $\begin{array}{c}\text { Elevated IOP } \\
\text { cataract }\end{array}$ & $\begin{array}{l}\text { Intravitrea } \\
1 \text { injection } \\
\text { every } 3-4 \\
\text { weeks }\end{array}$ & [232] \\
\hline
\end{tabular}

\section{Ophthalmic adverse effects of corticosteroids}

Ophthalmic corticosteroids adversely affect different parts of the human eye, from the outer eye layers of the eye, mainly the cornea to the orbital fat as well as the optic nerve. The two major ( $>10 \%$ of the treated population) ocular side effects include elevation of IOP and cataract $[6,220]$. The side effects of corticosteroids can be classified as those caused by systemic administration, intraocular injection, implants, or from topical administration $[61,233]$.

Table 4 summarizes the most common ocular side effects of corticosteroids following different methods of dosing.

Table 4 Summary of the most common adverse effects associated with the administration of corticosteroids via different routes.

\begin{tabular}{|c|c|c|c|}
\hline Topical administration & Systemic administration & Periocular injection & Intraocular injection \\
\hline \multirow{2}{*}{$\begin{array}{ll}\text { - } & \text { Increased IOP [234]. } \\
\text { - } & \text { Posterior subcapsular } \\
& \text { cataract [235] }\end{array}$} & \multirow{2}{*}{ 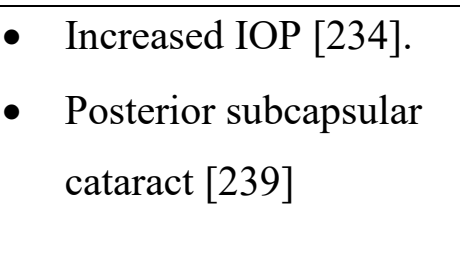 } & $\begin{array}{c}\text { Corticosteroids related } \\
\text { side effects }\end{array}$ & $\begin{array}{l}\text { Corticosteroids related } \\
\text { side effects }\end{array}$ \\
\hline & & - Elevated IOP [243] & $\begin{array}{ll}\text { - } & \text { Cataract [244] } \\
\text { - } & \text { Elevated IOP }[245,246]\end{array}$ \\
\hline
\end{tabular}


- Decreased resistance to infection [16].

- Delayed corneal and scleral wounds healing [236].

- Mydriasis [237].

- Ptosis [238]

- Retinal embolic phenomenon [16]

- Optic atrophy [16].
- Papilledema [240].

- Subconjunctival or retinal hemorrhages [16].

- Central serous chorioretinopathy [241].

- Retinal embolic phenomenon (secondary to injection) [242].

- Eyelid/conjunctival atrophy [16].
- Cataract formation [174]

Injection related side
effects

Injection related side effects

- Ocular pain [243]

- Decrease visual acuity [16]

- Subconjunctival hemorrhage [248]

- Globe perforation [249]

- Retrobulbar hemorrhage [250].
- Retinal hemorrhages [251].

- Retinal degeneration [171].

- Periocular atrophy or fibrosis [252].

- Endophthalmitis [239].

- Ocular infection [253].

- Vitreous hemorrhage [254].

- Bacterial infection [180]

\subsection{Corticosteroid-induced IOP elevation (ocular hypertension)}

A major problematic complication of glucocorticoid therapy is the rise in the IOP, which at sufficient elevation and duration without treatment may lead to impairment of the optic nerve, resulting in corticosteroid-induced glaucoma [14]. This can occur when corticosteroids are administered exogenously through all modes of administration (topical, periocular, intravitreal, or systemic administration) [255-258] and the rise in 
IOP happens after repeated doses of conventional corticosteroid ophthalmic eye drops [105]. Interestingly, certain health conditions, such as Cushing's syndrome, wherein endogenous production of corticosteroids is elevated, could increase IOP [259].

Patients with elevated IOP may have symptoms of headache, eye pain and reduced visual acuity [260]. The first report of increased IOP induced by locally administered corticosteroids was described by Francois [14]. Armaly and Becker [261-263] classified populations into low, intermediate and high responders depending on IOP elevation following topical administration of corticosteroids and related it to the inheritance of primary open-angle glaucoma (POAG) [261].

The elevated IOP and glaucoma development more probably occur in corticosteroidresponsive individuals than in those non-responsive. It is found that about $18 \%$ to $36 \%$ of the general population had a moderate increase of $5 \mathrm{~mm} \mathrm{Hg}$ or more in IOP following topical corticosteroid administration $[121,264]$. However, 46 to $92 \%$ of patients with POAG and 5 to $6 \%$ of the general population can show a significant and potentially damaging increase in IOP after topical corticosteroid administration [264-266]. This indicates that patients with POAG and glaucoma suspects show a higher incidence of IOP elevation following topical corticosteroid administration [261].

\subsubsection{Mechanism of corticosteroid-induced IOP elevation}

The exact mechanism by which corticosteroids induce an elevation in IOP remains inconclusive. Trabecular meshwork cells, which normally drain approximately $90 \%$ of the aqueous humor and contain a great number of corticosteroid receptors, have been hypothesized to have a key role in the incidence of corticosteroid-induced IOP elevation [229, 267, 268]. Figure 4 showed the proposed mechanisms of corticosteroid-induced IOP elevation.

The administered corticosteroids could enter the trabecular meshwork cells, leading to engagement of corticosteroid receptors and changes in the expression of trabecular meshwork genes [269, 270]. It is assumed that these changes in gene expression result in alterations in the extracellular matrix and amorphous granular material accumulated below the endothelial lining of the canal of Schlemm, thereby increasing the thickness of the trabecular beams and resulting in a decrease in the intertrabecular spaces. All these changes may increase the resistance of aqueous flow and elevate IOP [264, 267]. 
An alternative theory assumes that the elevation of IOP results from the stabilization of lysosomal membrane enzymes by the administered corticosteroids and inhibition of lysosomal enzymes release [271]. This results in decreasing the degradation of glycosaminoglycans (GAG) by these enzymes and consequent accumulation of GAG in the polymerized form in the trabecular meshwork, thereby decreasing aqueous outflow and elevating IOP $[16,272]$.

A third explanation that has been proposed makes the assumption that corticosteroids cause swelling of the collagen strands of the trabecular meshwork by increasing the water-binding capacity of the mucopolysaccharides and decreasing the trabecular meshwork phagocytic activity, ultimately resulting in accumulation of cellular debris, blockage of the outflow pathways, resistance to aqueous outflow, and IOP elevation [273].

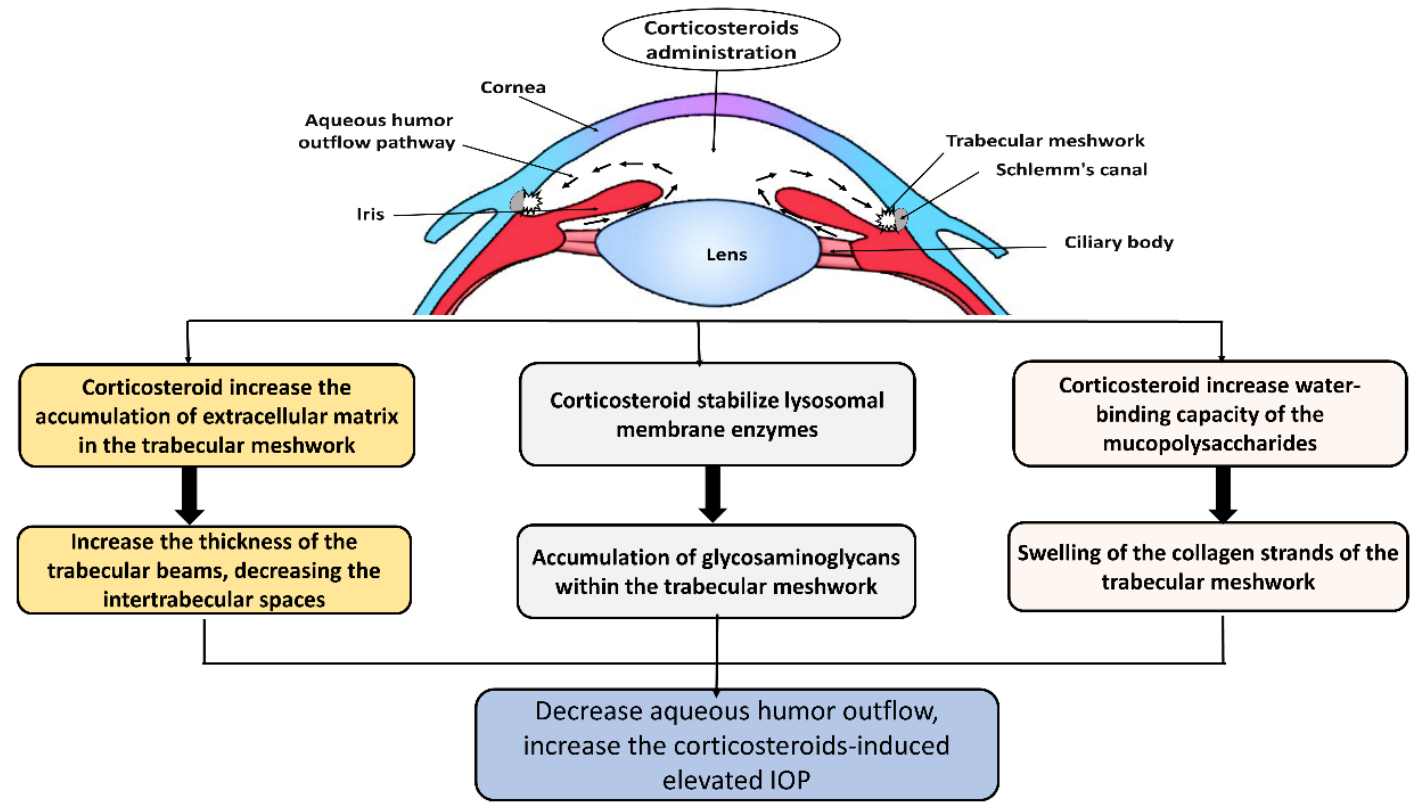

Figure 4 Graphical illustration of proposed mechanisms of corticosteroid-induced elevation of intraocular pressure, modified from [274]

\subsubsection{Factors affecting corticosteroid-induced IOP elevation}

\subsubsection{Effect of age}


The elevation of IOP as a result of corticosteroid administration is found to be agedependent. Many reports revealed that children are greater steroidal responders compared to adults [105, 275-277]. It has been shown that children below the age of 10 were susceptible to developing rapid IOP elevation following topical corticosteroid administration. In patients aged between 7 to 21 years with inflammatory bowel disease and receiving oral corticosteroids, $31.5 \%$ were reported to be corticosteroid responders, with a raised IOP of at least $6 \mathrm{mmHg}$ greater than that in adults [234, 276, 277]. For more discussion and examples on the elevation of IOP with age in response to corticosteroids, the reader is referred to the review published by Jones and Rhee [105]

\subsubsection{Effect of type and properties of administered corticosteroids}

Elevation of IOP induced by corticosteroid administration seems to be closely linked to the potency, dose, and frequency of administration as well as the duration of therapy [16]. The less potent agents require a longer duration of therapy to produce increased IOP and the elevation is not as high as those induced by more potent agents [149]. Table 5 represents the relative anti-inflammatory properties of certain members of corticosteroids used for ocular diseases. The higher elevation in IOP with more potent agents is likely due to the higher affinity to glucocorticoids receptors located on cells of the trabecular meshwork.

Following 6 weeks of topical corticosteroid treatment at a fixed concentration of $0.1 \%$, the average increase in IOP for dexamethasone, fluorometholone, and medrysone is approximately $63 \%, 35 \%$ and $8 \%$, respectively. This trend could be attributed to the difference in potency of these agents [278]. The more potent corticosteroids result in corticosteroid-induced IOP elevation within a few weeks of treatment while less potent members may provoke IOP elevation within months [279]. Infrequently, potent topical corticosteroids may induce acute elevation of IOP within hours or days of administration [280]. The potency of administered corticosteroids and consequently their effect on IOP depends on many factors such as drug structure and physicochemical properties [281]. It is found that only steroids that can penetrate into the anterior chamber induce elevated IOP. For example, medrysone (1\%) which is hydrophilic and with low potency, caused a $1.0 \mathrm{~mm} \mathrm{Hg}$ increase in IOP, while more potent corticosteroids such as prednisolone acetate $(1 \%)$ and dexamethasone acetate $(0.1 \%)$, 
which are lipophilic prodrugs, were found to cause a 10 and $22 \mathrm{~mm} \mathrm{Hg}$ increase in IOP, respectively $[282,283]$. This is attributed in part to their enhanced corneal permeability as a result of the increased lipophilicity.

Difluprednate (difluoroprednisolone butyrate acetate), which is a prednisolone derivative with high potency due to its increased lipophilicity compared to prednisolone, was found to cause elevation of IOP that was two-fold greater than prednisolone when used in postoperative inflammation treatment [284].

In addition, there is a strong relationship between corticosteroid-induced IOP and the dose of administered agents. Tripathi et al. [234] found that for each $10 \mathrm{mg}$ increase in a daily dose of prednisolone there was a $1.4 \mathrm{~mm} \mathrm{Hg}$ elevation in the mean IOP [234]. In addition, the IOP is affected by different forms of the same drug. For instance, triamcinolone acetonide (minimally water-soluble form) was found to produce sustained, elevated IOP for 6 months following sub-tenon injection. However, its diacetate form (moderately water-soluble form) had a less sustained effect on IOP [285, 286]. Generally, the increase of IOP has been reported to happen over weeks and in some cases, years with topical and systemic corticosteroids administration, respectively [105].

Table 5 Relative anti-inflammatory properties of certain ocular corticosteroids [240, 287, 288].

\section{Corticosteroids agents}

Relative anti-inflammatory potency

\begin{tabular}{cc}
\hline Hydrocortisone & 1 \\
\hline Prednisolone/prednisone & 4 \\
\hline Methyl prednisone & 5 \\
\hline Triamcinolone & 5 \\
\hline Fluocinolone acetonide & 25 \\
\hline Betamethasone & 25 \\
\hline Dexamethasone sodium phosphate & 25 \\
\hline Dexamethasone & $25-30$ \\
\hline
\end{tabular}




\subsubsection{Effect of concurrent diseases and the race}

The prevalence of corticosteroid-induced IOP elevation was found to be affected by the concurrent disease. Patients with type-1 diabetes mellitus [289], high myopia [290] and men with connective tissue diseases [291] are at increased risk of steroid-induced IOP elevation. A positive relationship exists between the development of open-angle glaucoma and the incidence of systemic hypertension and migraine [292]. Patients with POAG are at increased risk for the rise of IOP when treated with corticosteroids for ocular inflammatory conditions. For example, topical dexamethasone $0.1 \%$ eye drops for one month led to an increase in IOP by $>6 \mathrm{mmHg}$ in $90 \%$ of treated patients with coexisting POAG [105].

Patients with excess production of endogenous corticosteroids, such as in Cushing's syndrome secondary to adrenal adenoma, carcinoma or adrenal hyperplasia, are found to be more susceptible to corticosteroid-induced IOP elevation, but the elevated IOP of such patients usually returns to its normal levels following adrenalectomy [293, 294]. Corticosteroids (glucocorticoids and mineralocorticoids) and cortisol have been found to be a constant component of the aqueous humor and have been measured by isotope dilution techniques and radioimmunoassay; their concentrations in the aqueous humor are lower than the plasma level [295]. It was found that the concentration of cortisol in the aqueous humor and plasma was elevated in patients suffering from various eye diseases. This indicates the possible role of these endogenous hormones in the development of some eye diseases, especially those characterized by the elevated IOP [296]. Furthermore, the Baltimore study (Baltimore Eye Survey) revealed that black Americans are 3 to 4 times more susceptible to the incidence of POAG than white Americans [297].

\subsubsection{Non-ocular routes of administration of corticosteroids can potentially harm the eye}

Corticosteroids are commonly administered as nasal sprays or inhalations for treatment of different respiratory disorders including allergic rhinitis and asthma. Patients receiving high doses of inhaled corticosteroids for prolonged durations are at risk of corticosteroid-induced IOP elevation [14, 298]. 
Spiliotopoulos et al. [299] studied the effect of inhaled corticosteroids on the IOP. An aerosol nasal spray comprising $120 \mu \mathrm{g}$ tramazoline hydrochloride and $20 \mu \mathrm{g}$ dexamethasone was inhaled by 54 patients, once daily. Results showed that no change in the IOP was reported in about $66.7 \%$ of patients, while $11.1,9.3,5.6$, and $7.4 \%$ had an IOP elevation of 1, 2, 3 and $4 \mathrm{mmHg}$, respectively [299]. Inhaled and nasal steroids for 3 months have been associated with increased risk of elevation of IOP [257, 298].

Also, topical skin administration of corticosteroids is widely used for the treatment of various dermatological diseases such as vitiligo, acne vulgaris, and atopic dermatitis. Long term topical use of corticosteroid ointment has been reported to cause open-angle glaucoma [300]. Also, cosmetic products (facial lotions and creams) with corticosteroids components, may induce elevated IOP after application to the periocular region for a prolonged time [300, 301].

\subsubsection{Effect of administered pharmaceutical ingredients and formulations}

Ophthalmic formulations that were able to increase the corneal contact time as microsuspensions [161], gels and viscous formulations [302] can increase exposure duration or the corneal permeation and raise the concentrations/exposure of loaded corticosteroids in the aqueous humor. Additives such as cyclodextrin polymer leading to enhancement of corticosteroid solubility can consequently increase corneal permeability. Topical administration of an aqueous drop containing dexamethasonecyclodextrin inclusion complexes increased the aqueous humor concentration of dexamethasone by approximately 2.6 times in the AUC when compared to the marketed available solution eye drop of $0.1 \%$ dexamethasone alcohol following $1.9 \mathrm{~h}$ administration [120].

For intraocular corticosteroids implants dosage form, elevated IOP remains a common side effect which appears to mirror the drug release/concentration in the eye since it returns to the normal baseline when the drug is depleted from the implanted devices [303]. Ozurdex ${ }^{\circledR}$ (dexamethasone) implant resulted in a temporary elevation in IOP [28]. Not only the type of implanted corticosteroid but also the dose and position of the implant have a great effect on the induced IOP elevation. As previously discussed, minimizing the exposure of trabecular meshwork to corticosteroids by posterior positioning of the implanted devices leads to lower elevation in IOP. This was observed 
with fluocinolone acetonide implants as Iluvien ${ }^{\circledR}$ and Retisert $^{\circledR}$. Iluvien ${ }^{\circledR}(0.19 \mathrm{mg})$ led to a 7 -fold more lowering in elevation of IOP than Retisert ${ }^{\circledR}(0.59 \mathrm{mg})$. This could also be attributed in part to the markedly lower dose of Iluvien ${ }^{\circledR}$ than Retisert ${ }^{\circledR}$ implant [30]. Nano-sized drug delivery systems have been recorded as playing a role in controlling the resultant elevated IOP of the administered corticosteroids. Gaafer et al. [50] studied the effects of different forms of prednisolone: prednisolone acetate (a less soluble form) and prednisolone Na phosphate (a soluble form) on elevated IOP. Their results revealed that both prednisolone $\mathrm{Na}$ phosphate solution and prednisolone acetate suspension showed fast absorption with a steep elimination phase compared with prolonged and controlled absorption recorded for nano-sized elastic niosomes embodying alcohol (ethoniosomes) and prednisolone acetate or prednisolone Na phosphate. This resulted in a sharp and rapid increase in IOP for the suspension and solution dosage form compared to a controlled prolonged increase IOP and a lower $\Delta \mathrm{IOP}$ with ethoniosomes $[50]$.

\subsection{Corticosteroid-induced cataract formation}

A major side effect due to prolonged use of corticosteroids is the increased risk of development of cataracts [304]. Ageing is the major risk factor for cataract, the causes of which are considered to include an increase in oxidative stress and post-translational modification of the lens crysatllins that lead to aggregation and insolubilization [305]. Corticosteroid induced cataract formation was first reported by Black and colleagues, whose findings showed the development of cataract in $39 \%$ of rheumatic patients who had been on systemic treatment with corticosteroids [262]. The pathogenesis of corticosteroid-induced cataract has led to a number of hypotheses including water accumulation within lens fiber cells, lens protein aggregation due to inhibition of $\mathrm{Na}^{+}$ $/ \mathrm{K}^{+}$pump in the single epithelial layer of the human lens [306], and corticosteroid binding to lens proteins leading to the development of lysine-ketosteroids, covalent adducts, and lens opacities [307].

Figure 5 shows post-translational modifications of lens crystallins induced by the corticosteroid dexamethasone. This involves the reaction of the nucleophilic amino group in the lysine residues of lens proteins with the steroidal C20 keto group, resulting in the formation of a Schiff base [308]. Heyns rearrangement of the formed Schiff base 
leads to the formation of a stable ketoamine adduct. The resultant steroidal-protein adducts, with their large molecular weight, could alter the normal structure of lens proteins, leading to cataract formation [309]. This hypothesis is supported by in vitro observation of rabbit lens opacification following exposure to corticosteroids. The resultant opacification was similar to those formed in humans $[310,311]$.

Other theories include increased plasma and aqueous humor glucose level, inhibition of glucose-6-phosphate-dehydrogenase enzymes, and inhibition of RNA synthesis [312]. The incidence of corticosteroid-induced cataract increases with increasing dose and duration of treatment and individual variations in susceptibility [313]. Cataract formation may result from topical, intraocular, or systemic administration of corticosteroids. According to a population-based study, inhaled budesonide or beclomethasone $(1000 \mu \mathrm{g} / \mathrm{d})$ for over 2 years led to three times increase in the risk of cataract surgery [314]. The risk of development of corticosteroid-induced cataracts is not fully understood but it may be related to the intraocular penetration of corticosteroids and the duration of therapy.

It has been noticed that $0.1 \%$ fluorometholone has a low capacity for elevation of the IOP, with poor penetration into intraocular tissues [315]; however, it has been reported to induce cataract formation after a period of 4 months application [315]. The development of cataract may still occur, even if the administered corticosteroid dose is decreased; however, drug discontinuation may prevent further damage to crystallins and cataract formation or it may reverse the lens opacification [316].

Interestingly, animal studies showed that tocopherol (vitamin E) administered topically or systemically is useful as a prophylactic treatment against steroid-induced cataract in animal models [317]. More recently, sacrificing glycating agents such as L-carnosine could spare native crystallins from Heyns rearrangement by interacting with carbonyl groups instead of crystallins and hence, they act as prophylactic agents against corticosteroid-induced cataract formation [318]. However, further clinical studies are needed to elucidate and support these claims. 


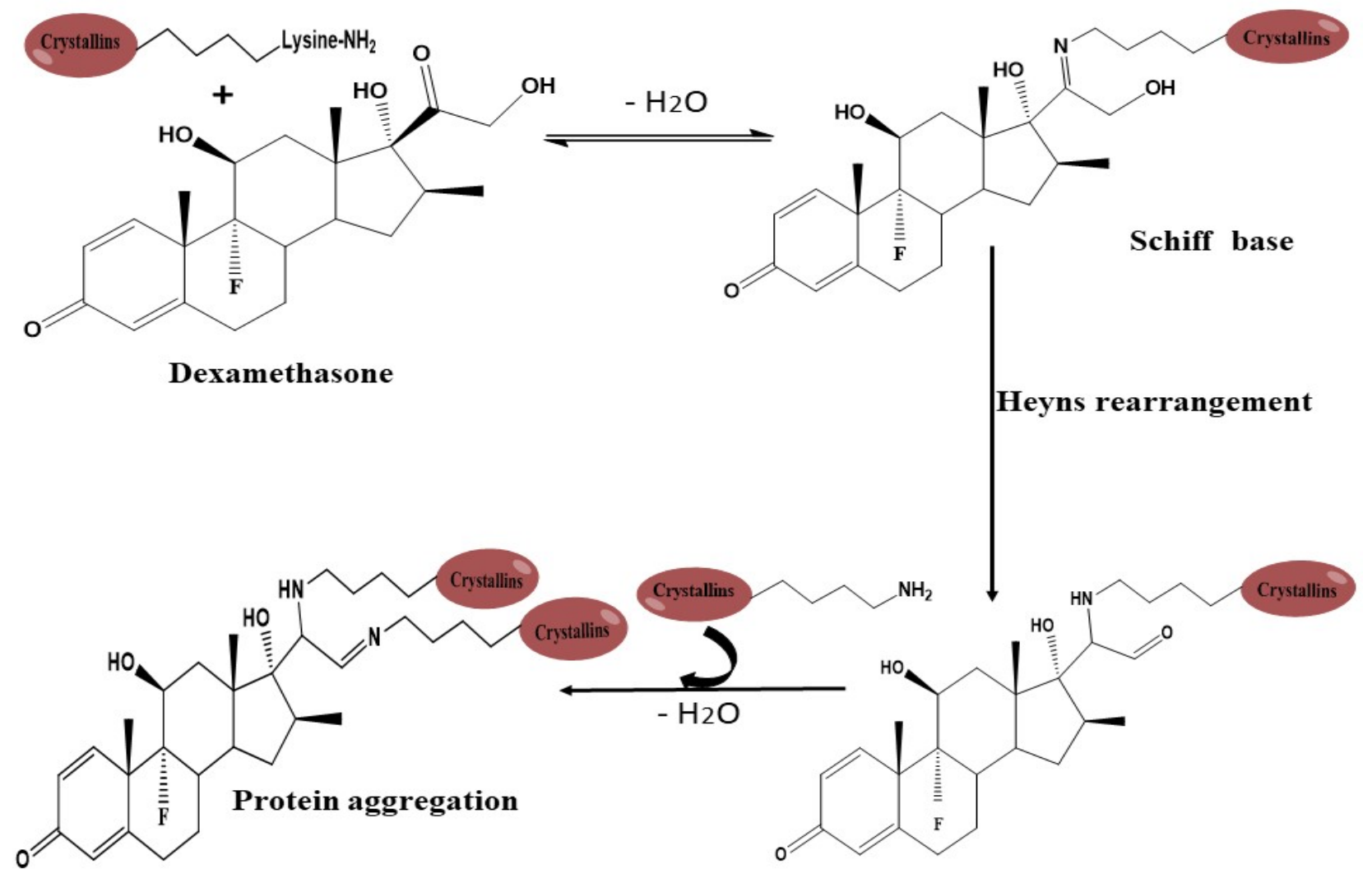

Figure 5 Corticosteroid-induced post-translational modifications of lens proteins (crystallins). Terminal free amino acids of lysine residues interact with carbonyl $(\mathrm{C}=\mathrm{O})$ groups of corticosteroid and forms Heyns rearrangement leading to crystallin aggregation and clouding of the human lens, modified from [319]. 


\section{Approaches to avoid and minimize corticosteroid-induced ocular complications}

General principles that should be followed with corticosteroid administration to prevent and/or minimize the development of corticosteroid-induced ocular complications are as follows: a) ophthalmic examinations should be conducted every 6 months for patients receiving long term treatment with ocular corticosteroids; b) appropriate dosage forms and routes of administration should be carefully selected according to the disease to be treated [27, 242]; the healthcare provider should take into account the risk/ benefit ratio when selecting specific drugs, their dose, and duration [242, 320]. c) Targeted therapy is preferred more than generalized therapy [242] and in some cases, sustained-release drug products may be more appropriate for reducing the frequency of visits, injections and systemic side effects [321]. Long-acting implantable corticosteroids such as Ozurdex ${ }^{\circledR}$ and Retisert ${ }^{\circledR}$ can elevate IOP and induce cataract formation. Further studies are needed to optimize such corticosteroid implants in terms of the dose, duration of the activity, and placement.

Other suggestions have been discussed elsewhere such as concomitant administration of topical antiglaucomic agents during corticosteroids therapy for life-long visionthreatening ocular diseases such as AMD and use of steroid receptor antagonists such as mifepristone [14]. However, none of these approaches were approved for clinical use and further clinical studies are needed.

Nonsteroidal anti-inflammatory drugs (NSAIDs) could serve as potential alternatives to corticosteroids in some ophthalmic inflammatory conditions. They are not accompanied by the risk of elevated IOP or increased susceptibility to infection [322]. For example, a double-blind parallel comparison of dexamethasone with the NSAID ketorolac demonstrated that ketorolac has an effect similar to dexamethasone in decreasing the postoperative inflammation after cataract surgery [323].

Similarly, the anti-inflammatory effect of diclofenac sodium was comparable to that of dexamethasone sodium phosphate at equal concentrations $(0.1 \%)$ [324]. The results showed similar reduction in the aqueous cell counts or equivalent anti-inflammatory efficacy [324]. Ocular side effects reported with NSAIDs include burning and stinging to more serious ocular complications like corneal erosion and corneal ulceration and melting $[325,326]$. 
Immunosuppressants are another drug class that can be used as an alternative to corticosteroids for treatment of ocular inflammatory conditions without causing the sight impairment side effects of corticosteroids (ocular hypertension and cataract). This include cyclosporine which is an immunosuppressant drug is available as an ophthalmic emulsion $\left(\right.$ Restasis $^{\circledR}$ ) for treatment of severe dry eye conditions and other inflammatory surface eye diseases. Tacrolimus $(0.1 \%)$ eye drops is another immunosuppressant agent used off-label by ophthalmologists to treat meibomian gland inflammation and allergic conjunctivitis [327].

\section{Future perspectives}

Corticosteroids, members of a class of highly potent ophthalmic anti-inflammatory agents, are used in treating inflammatory conditions affecting multiple tissue targets within the ocular surface, anterior and posterior segments of the eye. A variety of dosage forms are available for ophthalmic use of corticosteroids, including solutions, suspensions, emulsions, ointments, gels, puncta plug, biodegradable implant for injection (preformed as well as in situ forming), and non-degradable implants for injection. Additionally, iontophoretic delivery systems are currently being evaluated. Iontophoretic drug delivery us currently being explored in clinical trials. This approach to enhance ocular drug delivery was summarized by Eljarrat-Binstock and Domb [328]. This enhances the delivery of administered drugs based on their charge, using a low electric current. When an ionizable drug substance is subjected to an electrical current, it may result in increased flux across biological membranes due to electron repulsion or electroosmotic flow [329]. Interestingly, this technology is currently under clinical development for corticosteroid delivery. The EyeGate II delivery system (EGDS), an innovative ocular iontophoresis delivery system, has been developed to maintain drug levels in the anterior and posterior eye segments [330]. The EGDS has been studied for the delivery of dexamethasone sodium phosphate (EGP 437) for the treatment of anterior uveitis and dry eye. The outcomes of clinical studies revealed the safety and efficacy of the product with lower elevation in IOP; consequently, it may provide a potential alternative for the conventional delivery systems [331]. However, wide patient acceptance of electrical current based delivery of drugs has yet to be established for a sensitive organ like the eye. A more patient friendly approach is Dextenza ${ }^{\circledR}$ punctual 
inserts/plugs of dexamethasone that is inserted non-invasively into the punctum (an opening in the eye lid through which tear fluid drain) of the affected eye after cataract surgeries for treating pain and inflammation post-cataract surgery. Dextenza ${ }^{\circledR}$ punctual inserts/plugs can provide sustained release of the corticosteroid drug to the ocular surface for up to 4 weeks [332].

Due to their potency, very low doses of corticosteroids are needed for treating eye diseases locally, relative to their systemic doses. This minimizes systemic side effects. Although the use of corticosteroids for the treatment of eye diseases is widespread and beneficial, the formulation of novel approaches for corticosteroid usage with minimal local side effects is much needed. Key local side effects are intraocular pressure elevation and cataract formation.

A major approach to minimize the side effects of corticosteroids in ophthalmic use is based on retrometabolic drug design, which was first introduced in 1970 by Bodor and colleagues [333]. This technique is based on developing corticosteroids that will produce their desired therapeutic effects and quickly biotransformed into inactive moieties in order to eliminate undesired side effects. One promising synthetic corticosteroid designed by the retrometabolic technique is loteprednol etabonate. It is commonly known as a soft drug and belongs to a unique class of corticosteroids that were designed to maintain effective anti-inflammatory activity while reducing the risk related to this group of medication, especially that of induced IOP elevation and cataract formation [309]. It is designed with two ester linkages at $17 \alpha$ - and $17 \beta$-positions. It loses its corticosteroid activity upon hydrolysis of either ester bond in cornea and aqueous humor, producing inactive metabolites [334, 335]; . Many clinical studies have revealed the effectiveness of loteprednol etabonate in numerous ocular inflammatory conditions including giant papillary conjunctivitis [336], allergic conjunctivitis [337], anterior uveitis [338], keratoconjunctivitis [71], and postoperative inflammation [338]. Interestingly, the risk of elevation in IOP by loteprednol etabonate was found to be low (similar to that observed with the vehicle) and markedly lower than that observed with other corticosteroids, even in steroid responder patients [339]. Clinical studies were performed to estimate the efficacy of loteprednol etabonate $0.5 \%$ against prednisolone acetate $1.0 \%$ for controlling postoperative inflammation following cataract surgery. The results indicated that both loteprednol etabonate and prednisolone acetate were equivalent in the control of inflammation after cataract surgery. However, treatment 
with loteprednol etabonate resulted in elevation in the IOP of approximately $60 \%$ of that produced by prednisolone acetate $1.0 \%$. This study, however, was an acute study spanning 3 days. The product literature for $0.5 \%$ loteprednol etabonate indicates that it is slightly less effective in a 28-day study for treating acute anterior uveitis when compared to $1 \%$ prednisolone acetate (resolutions in $72 \%$ vs $87 \%$ of patients) with the incidence of $10 \mathrm{~mm} \mathrm{Hg}$ or greater increase in IOP in $1 \%$ of the patients with loteprednol etabonate vs. $6 \%$ for prednisolone acetate. The product literature still carries the warning of the potential for cataract and IOP elevation. Ophthalmic suspensions of $0.5 \%$ and $0.2 \%$ were the first commercial formulations for loteprednol etabonate approved by the FDA in 1998. Recently, many formulations have been developed as suspensions, ointments and gels [338, 340, 341].

In addition to drug design by retrometabolic approaches (e.g., loteprednol etabonate), development of new corticosteroids with therapeutics benefits that can outweigh side effects has been an endeavour. For example, corticosteroids conjugated with glycine or formation of PEGylated corticosteroids (conjugation with polyethylene glycol) have been utilized to generate new members of corticosteroids with larger molecular weight and more hydrophilicity. Such approaches could undermine corticosteroids lipophilicity and cell permeability [83, 85].

Thirdly, alternative choices to corticosteroids notably NSAIDS and other compounds are being investigated. NSAIDs have been utilized in ophthalmology for the treatment of inflammation, scleritis, and to protect from and treat cystoid macular oedema secondary to cataract surgery [342-345]. Recently many NSAIDs have become available and these could be alternatives to corticosteroids with fewer treatment-related serious ocular adverse reactions. Examples of NSAID include diclofenac, nepafenac, flurbiprofen, ketorolac and suprofen with anti-inflammatory activity similar to that of prednisolone acetate in certain cases [346-348]. It has been shown that flurbiprofen did not alter the IOP level in high responder patients [349]. In experimental studies, celecoxib, a nonsteroidal anti-inflammatory drug that is a specific inhibitor of COX-2, has been shown to be effective in minimizing vascular biochemical and pathological changes in the diabetic retina [350-352]. These could be alternatives to corticosteroids, especially in patients with a high risk of IOP elevation. 
Cyclosporine and tacrolimus are not corticosteroids but show immunosuppressant effects. These two drugs have been used as topical emulsion and topical eye drops, respectively for treatment of various inflammatory diseases such as severe allergic conjunctivitis, keratoconjunctivitis sicca (severe dry eye), scleritis and anterior uveitis [353, 354]. Topical cyclosporine and tacrolimus are generally safe from typical sight impairing side effects of corticosteroids (cataract and ocular hypertension). Other less serious side effects reported for topical tacrolimus include transient burning and stinging and increased risk of ocular infection [353]. Ocular pain and burning are the most reported side effects for topical cyclosporine $0.05 \%$ emulsion [354]. These two drugs cyclosporine and tacrolimus can be considered potential alternatives to corticosteroids for treatment of the above-mentioned inflammatory conditions in glaucomic patients.

\section{Conclusions}

Ocular corticosteroids are amongst the most widely used medications for controlling ocular inflammatory conditions. They are administered using various routes of administration and different delivery systems. Topical ophthalmic dosage forms are commonly used for the treatment of diseases of the ocular surface and anterior segment; alternative delivery routes such as periocular, suprachoroidal and intravitreal routes are useful for drug delivery to the posterior segment of the eye. Although corticosteroids are potent and generally effective, they pose a significant risk of causing serious ocular adverse effects including cataract formation and elevated IOP. The severity of the corticosteroid associated side effects mainly relies on the potency of the administered corticosteroids, size of the dose, duration of therapy and the drug delivery route. Topical corticosteroids can induce rapid elevation of IOP within few hours postadminstration; on contrary, systemic corticosteroids administration requires high doses and prolonged treatment periods. Intraocular implants $\left(\right.$ Ozurdex $^{\circledR}$, Iluvien ${ }^{\circledR}$ and Retisert ${ }^{\circledR}$ ) have greatly reduced systemic side effects but more chronic delivery with these systems raises the probability of incidence of cataracts and elevated IOP in majority of patients. Innovative ideas like Dextenza ${ }^{\circledR}$ plugs can provide prolonged treatment and the therapy can be terminated if the side effects escalated, by removing the corticosteroid plug from the administration site. NSAIDs could be useful alternatives for corticosteroids; 
however, they are not as broad in their anti-inflammatory activity as corticosteroids. Future line of research would further study the mechanisms of corticosteroid-induced adverse effects at sustained ultralow levels vs. pulsatile sustained delivery.

\section{Conflict of Interest}

The authors report no conflict of interest nor financial interest

\section{References}


Dell, S.J., et al., A controlled evaluation of the efficacy and safety of loteprednol

etabonate in the prophylactic treatment of seasonal allergic conjunctivitis. American journal of ophthalmology, 1997. 123(6): p. 791-797.

Study, T.L.E.U.U., Controlled evaluation of loteprednol etabonate and prednisolone acetate in the treatment of acute anterior uveitis. American Journal of Ophthalmology, 1999. 127(5): p. 537-544.

Pflugfelder, S.C., S.C. Tseng, and A.J. Huang, Non-preserved topical corticosteroid for treatment of dry eye, filamentary keratitis, and delayed tear clearance (or turnover), 2000, Google Patents.

Pimentel, M.A., et al., Assessment of the accuracy of using ICD-9 codes to identify uveitis, herpes zoster ophthalmicus, scleritis, and episcleritis. JAMA ophthalmology, 2016. 134(9): p. 1001-1006.

Munir, W.M., et al., Intravitreal triamcinolone for treatment of complicated 5. proliferative diabetic retinopathy and proliferative vitreoretinopathy. Canadian journal of ophthalmology, 2005. 40(5): p. 598-604.

Allergan, I., OZURDEX ${ }^{\circledR}$ product information, I. Allergan, Editor 2014, Allergan, Inc. . Solomon, S.D., et al., Diabetic retinopathy: a position statement by the American Diabetes Association. Diabetes care, 2017. 40(3): p. 412-418.

Meredith, T.A., et al., Postinjection endophthalmitis in the comparison of agerelated macular degeneration treatments trials (CATT). Ophthalmology, 2015. 122(4): p. 817-821.

Struck, H. and A. Bariszlovich, Comparison of $0.1 \%$ dexamethasone phosphate eye gel (Dexagel) and 1\% prednisolone acetate eye suspension in the treatment of postoperative inflammation after cataract surgery. Graefe's archive for clinical and experimental ophthalmology, 2001. 239(10): p. 737-742.

Schwartz, S.G., et al., Update on corticosteroids for diabetic macular edema. Clinical Ophthalmology, 2016. 10: p. 1723-1730.

Haller, J.A., Intravitreal corticosteroids: a review of therapeutic and surgical 11. applications. Retina Today, 2009. S1: p. 1-15.

Ayalasomayajula, S.P., P. Ashton, and U.B. Kompella, Fluocinolone inhibits VEGF expression via glucocorticoid receptor in human retinal pigment epithelial (ARPE-19) cells and TNF- $\alpha$-induced angiogenesis in chick chorioallantoic membrane (CAM). Journal of ocular pharmacology and therapeutics, 2009. 25(2): p. 97-104.

K Suresh, P. and A. K Sah, Patent perspectives for corticosteroids based ophthalmic therapeutics. Recent patents on drug delivery \& formulation, 2014. 8(3): p. 206-223. Tripathi, R.C., et al., Corticosteroids and glaucoma risk. Drugs \& aging, 1999. 15(6): p. 439-450.

Abdelkader, H., R. Alany, and B. Pierscieonek, Age-related cataract and drug 15. therapy: opportunities and challenges for topical antioxidant delivery to the lens. J. Pharm. Pharmacol. 67: p. 537-550.

Carnahan, M.C. and D.A. Goldstein, Ocular complications of topical, peri-ocular, and systemic corticosteroids. Current opinion in ophthalmology, 2000. 11(6): p. 478-483. Kwatra, G. and S. Mukhopadhyay, Topical Corticosteroids: Pharmacology, in A treatise on topical corticosteroids in dermatology. 2018, Springer. p. 11-22. Popper, T.L., et al., Structure-activity relationships of a series of novel topical corticosteroids. Journal of steroid biochemistry, 1987. 27(4-6): p. 837-843. He, Y., et al., Structures and mechanism for the design of highly potent 19. glucocorticoids. Cell research, 2014. 24(6): p. 713-726.

Crim, C., L.N. Pierre, and P.T. Daley-Yates, A review of the pharmacology and pharmacokinetics of inhaled fluticasone propionate and mometasone furoate. Clinical therapeutics, 2001. 23(9): p. 1339-1354. . 
Salter, M., et al., Pharmacological properties of the enhanced-affinity glucocorticoid

fluticasone furoate in vitro and in an in vivo model of respiratory inflammatory

disease. American Journal of Physiology-Lung Cellular and Molecular Physiology,

2007. 293(3): p. L660-L667.

Musson, D., A. Bidgood, and O. Olejnik, An in vitro comparison of the permeability of

22. prednisolone, prednisolone sodium phosphate, and prednisolone acetate across the NZW rabbit cornea. Journal of Ocular Pharmacology and Therapeutics, 1992. 8(2): p. 139-150.

Thakur, A., R.S. Kadam, and U.B. Kompella, Influence of drug solubility and 23. lipophilicity on transscleral retinal delivery of six corticosteroids. Drug metabolism and disposition, 2011. 39(5): p. 771-781.

Eliott, D. and P.K. Rao, Surgical management of intraocular inflammation and infection. 2013: JP Medical Ltd.

Salama, A.H., A.A. Mahmoud, and R. Kamel, A novel method for preparing surfacemodified fluocinolone acetonide loaded PLGA nanoparticles for ocular use: in vitro and in vivo evaluations. AAPS pharmscitech, 2016. 17(5): p. 1159-1172.

Al-Muhammed, J., et al., In-vivo studies on dexamethasone sodium phosphate liposomes. Journal of microencapsulation, 1996. 13(3): p. 293-305.

Awan, M.A., et al., Penetration of topical and subconjunctival corticosteroids into human aqueous humour and its therapeutic significance. British Journal of Ophthalmology, 2009. 93(6): p. 708-713.

Malclès, A., et al., Safety of intravitreal dexamethasone implant (Ozurdex): the SAFODEX study. Incidence and risk factors of ocular hypertension. Retina, 2017. 37(7): p. 1352-1359.

Kompella, U., R.S. Kadam, and V.H.L. Lee, Recent advances in ophthalmic drug delivery. Ther. Deliv. , 2010 1: p. $435-456$.

Yang, Y., et al., Intravitreal corticosteroids in diabetic macular edema: 30. pharmacokinetic considerations. Retina (Philadelphia, Pa.), 2015. 35(12): p. 2440. CAS-No, C.C., Bristol-Myers Squibb Company. 2001. 31.

Arvas, S., O. Ocakoglu, and S. Ozkan, The capillary blood flow in ischaemic type central retinal vein occlusion: the effect of laser photocoagulation. Acta Ophthalmol Scand. , 2002 80: p. 490-494.

Chambers, W.A., Trivaris (triamcinolone acetonide injectable suspension) $80 \mathrm{mg} / \mathrm{mL}$ product information, I. Allergan, Editor 2008, Allergan, Inc.

YANG, Y., et al., Intravitreal corticosteroids in diabetic macular edema. Retina, 2015. 35: p. 2440-2449, .

Florence, A.T. and D. Attwood, The solubility of drugs, in Physichochemical Principles of Pharmacy, A.T. Florence and D. Attwood, Editors. 1988, MACMILLAN Press LTD: London. p. 153-182.

Moffat, A.C., et al., Clarke's analysis of drugs and poisons. Vol. 3. 2011: 36. Pharmaceutical press London.

CHAUDHARI, P.D. and U.S. DESAI, Formulation and evaluation of niosomal in situ gel of prednisolone sodium phosphate for ocular drug delivery. Int J Appl Pharm, 2019. 11: p. 97-116.

Jóhannesson, G., E. Stefánsson, and T. Loftsson, Microspheres and nanotechnology for drug delivery, in Retinal Pharmacotherapeutics. 2016, Karger Publishers. p. 93103.

Gan, L., et al., Self-assembled liquid crystalline nanoparticles as a novel ophthalmic delivery system for dexamethasone: improving preocular retention and ocular bioavailability. International journal of pharmaceutics, 2010. 396(1-2): p. 179-187. 
Bhagat, R., et al., Comparison of the release profile and pharmacokinetics of intact and fragmented dexamethasone intravitreal implants in rabbit eyes. Journal of Ocular Pharmacology and Therapeutics, 2014. 30(10): p. 854-858.

Yang, G., Y. Ran, and S.H. Yalkowsky, Prediction of the aqueous solubility: 41. comparison of the general solubility equation and the method using an amended solvation energy relationship. Journal of pharmaceutical sciences, 2002. 91(2): p. 517-533.

Gao, Y., et al., PLGA-PEG-PLGA hydrogel for ocular drug delivery of dexamethasone acetate. Drug development and industrial pharmacy, 2010. 36(10): p. 1131-1138.

Fialho, S.L. and A. Da Silva-Cunha, New vehicle based on a microemulsion for topical ocular administration of dexamethasone. Clinical \& experimental ophthalmology, 2004. 32(6): p. 626-632.

Papangkorn, K., et al., A Novel Ocular Drug Delivery System of Dexamethasone 44. Sodium Phosphate for Noninfectious Uveitis Treatment, in Advances in the Diagnosis and Management of Uveitis. 2018, IntechOpen.

Boone, A., A. Hui, and L. Jones, Uptake and release of dexamethasone phosphate

45. from silicone hydrogel and group I, II, and IV hydrogel contact lenses. Eye \& contact lens, 2009. 35(5): p. 260-267.

Ranch, K., et al., Development of in situ ophthalmic gel of dexamethasone sodium phosphate and chloramphenicol: a viable alternative to conventional eye drops. J Appl Pharm Sci, 2017. 7: p. 101-108.

EIShaer, A., et al., Nanoparticle-laden contact lens for controlled ocular delivery of prednisolone: Formulation optimization using statistical experimental design. Pharmaceutics, 2016. 8(2): p. 14.

Hayton, W.L., D.E. Guttman, and G. Levy, Effect of complex formation on drug absorption XI: Complexation of prednisone and prednisolone with dialkylpropionamides and its effect on prednisone transfer through an artificial lipoid barrier. Journal of pharmaceutical sciences, 1972. 61(3): p. 356-361.

Machatha, S.G. and S.H. Yalkowsky, Comparison of the octanol/water partition coefficients calculated by $C \log P^{\circledR}, A C D \log P$ and $K o w W i n{ }^{\circledR}$ to experimentally determined values. International journal of pharmaceutics, 2005. 294(1-2): p. 185192.

Gaafar, P.M., et al., Preparation, characterization and evaluation of novel elastic nano-sized niosomes (ethoniosomes) for ocular delivery of prednisolone. Journal of liposome research, 2014. 24(3): p. 204-215.

Katzer, T., et al., Prednisolone-loaded nanocapsules as ocular drug delivery system: development, in vitro drug release and eye toxicity. Journal of microencapsulation, 2014. 31(6): p. 519-528.

Diestelhorst, M., et al., Effect of dexamethasone $0.1 \%$ and prednisolone acetate $1.0 \%$ eye drops on the blood-aqueous barrier after cataract surgery: a controlled randomized fluorophotometric study. Graefe's archive for clinical and experimental ophthalmology, 1992. 230(5): p. 451-453.

Ibrahim, S.S., et al., Comparative effects of different cosurfactants on sterile 53. prednisolone acetate ocular submicron emulsions stability and release. Colloids and Surfaces B: Biointerfaces, 2009. 69(2): p. 225-231.

Yalkowsky, S.H. and S.C. Valvani, Solubility and partitioning I: solubility of 54. nonelectrolytes in water. Journal of pharmaceutical sciences, 1980. 69(8): p. 912922.

Leibowitz, H.M., et al., Penetration of topically administered prednisolone acetate into the human aqueous humor. American journal of ophthalmology, 1977. 83(3): p. 402-406. 
Elbialy, N.S., et al., Enhancement of the ocular therapeutic effect of prednisolone acetate by liposomal entrapment. Journal of biomedical nanotechnology, 2013. 9(12): p. 2105-2116.

Malaekeh-Nikouei, B., et al., Controlled release of prednisolone acetate from molecularly imprinted hydrogel contact lenses. Journal of Applied Polymer Science, 2012. 126(1): p. 387-394.

Schoenwald, R. and J. Boltralik, A bioavailability comparison in rabbits of two 58. steroids formulated as high-viscosity gels and reference aqueous preparations. Investigative ophthalmology \& visual science, 1979. 18(1): p. 61-66. Block, L. and R. Patel, Solubility and dissolution of triamcinolone acetonide. Journal 59. of Pharmaceutical Sciences, 1973. 62(4): p. 617-621.

Tao, Y. and J.B. Jonas, Intravitreal triamcinolone. Ophthalmologica, 2011. 225(1): p. 1-20.

Jonas, J., I. Kreissig, and R. Degenring, Intraocular pressure after intravitreal 61. injection of triamcinolone acetonide. British journal of ophthalmology, 2003. 87(1): p. 24-27.

Singh, K. and M. Mezei, Liposomal ophthalmic drug delivery system I. Triamcinolone acetonide. International journal of pharmaceutics, 1983. 16(3): p. 339-344. Jaffe, G.J., et al., Safety and pharmacokinetics of an intraocular fluocinolone 63. acetonide sustained delivery device. Investigative ophthalmology \& visual science, 2000. 41(11): p. 3569-3575.

Werawatganone, P., et al., Solubilization of fluocinolone acetonide by cosolvents and surfactants for buccal solution preparation. Thai Journal of Pharmaceutical Sciences (TJPS), 2018. 42(2).

Kiddee, W., et al., Intraocular pressure monitoring post intravitreal steroids: a systematic review. Survey of ophthalmology, 2013. 58(4): p. 291-310.

Jaffe, G.J., et al., Fluocinolone acetonide implant (Retisert) for noninfectious 66. posterior uveitis: thirty-four-week results of a multicenter randomized clinical study. Ophthalmology, 2006. 113(6): p. 1020-1027.

Vafaei, S.Y., et al., Controlled-release drug delivery system based on fluocinolone acetonide-cyclodextrin inclusion complex incorporated in multivesicular liposomes. Pharmaceutical development and technology, 2015. 20(7): p. 775-781.

Alberth, M., et al., Lipophilicity, solubility and permeability of loteprednol etabonate: a novel, soft anti-inflammatory steroid. J Biopharm Sci, 1991. 2(2): p. 115-125. Comstock, T.L. and H.H. DeCory, Advances in corticosteroid therapy for ocular 69. inflammation: loteprednol etabonate. International journal of inflammation, 2012. 2012.

Rajpal, R.K., et al., Efficacy and safety of loteprednol etabonate $0.5 \%$ gel in the 70. treatment of ocular inflammation and pain after cataract surgery. Journal of Cataract \& Refractive Surgery, 2013. 39(2): p. 158-167.

Pflugfelder, S.C., et al., A randomized, double-masked, placebo-controlled, 71. multicenter comparison of loteprednol etabonate ophthalmic suspension, $0.5 \%$, and placebo for treatment of keratoconjunctivitis sicca in patients with delayed tear clearance. American journal of ophthalmology, 2004. 138(3): p. 444-457.

Noh, G., et al., Development and evaluation of a water soluble fluorometholone eye drop formulation employing polymeric micelle. Pharmaceutics, 2018. 10(4): p. 208. Miyake, K., et al., Nepafenac $0.1 \%$ versus fluorometholone $0.1 \%$ for preventing cystoid macular edema after cataract surgery. Journal of Cataract \& Refractive Surgery, 2011. 37(9): p. 1581-1588.

Jamal, K.N. and D.G. Callanan, The role of difluprednate ophthalmic emulsion in clinical practice. Clinical ophthalmology (Auckland, NZ), 2009. 3: p. 381. . 
Kimura, M., et al., Compositions containing difluprednate, 2000, Google Patents. 75. Korenfeld, M., Difluprednate: changing the landscape of ocular pharmacology. Expert Review of Ophthalmology, 2008. 3(6): p. 619-625.

Chambless, S.L. and S. Trocme, Developments in ocular allergy. Current opinion in allergy and clinical immunology, 2004. 4(5): p. 431-434.

Bielory, L., Allergic and immunologic disorders of the eye. Part II: ocular allergy. Journal of Allergy and Clinical Immunology, 2000. 106(6): p. 1019-1032.

Abelson, M.B. and K. Schaefer, Conjunctivitis of allergic origin: immunologic 79. mechanisms and current approaches to therapy. Survey of ophthalmology, 1993. 38: p. 115-132.

Woods, A.C., Clinical and experimental observation on the use of ACTH and 80. cortisone in ocular inflammatory disease. American journal of ophthalmology, 1950. 33(9): p. 1325-1351.

Villanueva, J.R., L.R. Villanueva, and M.G. Navarro, Pharmaceutical technology can turn a traditional drug, dexamethasone into a first-line ocular medicine. A global perspective and future trends. International journal of pharmaceutics, 2017. 516(12): p. 342-351.

Rhen, T. and J.A. Cidlowski, Antiinflammatory action of glucocorticoids-new 82. mechanisms for old drugs. New England Journal of Medicine, 2005. 353(16): p. 17111723.

Jiang, C.L., et al., The novel strategy of glucocorticoid drug development via 83. targeting nongenomic mechanisms. Steroids 2015. 102 p. 27-31.

Stahn, C. and F. Buttgereit, Genomic and nongenomic effects of glucocorticoids. Nature Reviews Rheumatology, 2008. 4(10): p. 525.

Vandewalle, J., et al., Therapeutic mechanisms of glucocorticoids. Trends in 85. Endocrinology \& Metabolism, 2018. 29: p. 42-54.

Zhang, X., et al., Glucocorticoids: structure, signaling and molecular mechanisms in the treatment of diabetic retinopathy and diabetic macular edema

Curr Mol Med., 2014. 14: p. 376-384.

Idrees, F., et al., A review of anterior segment dysgeneses. Survey of ophthalmology, 2006. 51(3): p. 213-231.

McGhee, C., Pharmacokinetics of ophthalmic corticosteroids. The British journal of ophthalmology, 1992. 76(11): p. 681.

Pan, Q., et al., Corticosteroid-loaded biodegradable nanoparticles for prevention of corneal allograft rejection in rats. Journal of controlled release, 2015. 201: p. 32-40. Ciulla, T.A., et al., Corticosteroids in posterior segment disease: an update on new delivery systems and new indications. Current opinion in ophthalmology, 2004. 15(3): p. 211-220.

Bachu, R., et al., Ocular Drug Delivery Barriers-Role of Nanocarriers in the 91. Treatment of Anterior Segment Ocular Diseases. Pharmaceutics, 2018. 10(1): p. 28. Gaudana, R., et al., Ocular drug delivery. The AAPS journal, 2010. 12(3): p. 348-360. !!! INVALID CITATION !!! 93.

Guy, Y.J. and D.I. Friedman, Suspension of loteprednol etabonate for ear, eye, or nose treatment, 1996, Google Patents.

Ahmed, I., The noncorneal route in ocular drug delivery, in Ophthalmic drug delivery systems. 2003, CRC Press. p. 356-385.

Kompella, U., S. Vooturi, and R. Kadam, Topical ocular drug delivery, 2013, Google Patents. 
Lang, J.C. and M.M. Stiemke, Biological barriers to ocular delivery. Ocular 98. Therapeutics and Drug Delivery. A Multi-disciplinary Approach, 1995: p. 51-132. Davies, N.M., Biopharmaceutical considerations in topical ocular drug delivery. Clinical and Experimental Pharmacology and Physiology, 2000. 27(7): p. 558-562. Lang, J.C., Ocular drug delivery conventional ocular formulations. Advanced drug delivery reviews, 1995. 16(1): p. 39-43.

Lee, Y.H., U.B. Kompella, and V.H. Lee, Systemic absorption pathways of topically

99. applied Beta adrenergic antagonists in the pigmented rabbit. Exp. Eye Res., 1993 p. 341-349.

Vooturi, S., et al., Effect of particle size and viscosity of suspensions on topical Ocular 102. bioavailability of budesonide, a corticosteroid. J. Ocul. Pharmacol. Ther., 2020. 36: p. 1-6.

Yang, C.-q., W. Sun, and Y.-s. Gu, A clinical study of the efficacy of topical 103. corticosteroids on dry eye. Journal of Zhejiang University SCIENCE B, 2006. 7(8): $p$. 675-678.

Meehan, K., L. Vollmer, and J. Sowka, Intraocular pressure elevation from topical

104. difluprednate use. Optometry-Journal of the American Optometric Association, 2010. 81(12): p. 658-662.

Jones, R. and D.J. Rhee, Corticosteroid-induced ocular hypertension and glaucoma: a 105. brief review and update of the literature. Curr. Opin. Ophthalmol., 2006. 17: p. 163167.

Abdelkader, H. and R. G Alany, Controlled and continuous release ocular drug 106. delivery systems: pros and cons. Current drug delivery, 2012. 9(4): p. 421-430. McCluskey, P.J., H.M. Towle, and S. Lightman, Management of chronic uveitis. Bmj, 2000. 320(7234): p. 555-558.

Feiler, D.L., et al., Resolution of noninfectious uveitic cystoid macular edema with topical difluprednate. Retina, 2017. 37(5): p. 844-850.

Sherif A. Gaballa, O.H.E.G., Hossam Moharram, Hamdy Abdelkader Preparation and evaluation of cubosomes/cubosomal gels for ocular delivery of beclomethasone dipropionate for management of uveitis Pharmaceutics researches, 2020.

Hamashige, S. and A.M. Potts, The penetration of cortisone and hydrocortisone into the ocular structures. American journal of ophthalmology, 1955. 40(5): p. 211-216. TANIGUCHI, K., et al., Efficacy of a liposome preparation of anti-inflammatory 111. steroid as an ocular drug-delivery system. Journal of pharmacobio-dynamics, 1988. 11(1): p. 39-46.

Gaballa, S.A., O.H. El Garhy, and H. Abdelkader, Cubosomes: composition, 112. preparation, and drug delivery applications. Journal of advanced Biomedical and Pharmaceutical Sciences, 2020. 3(1): p. 1-9.

Pepić, l., et al., A nonionic surfactant/chitosan micelle system in an innovative eye drop formulation. Journal of pharmaceutical sciences, 2010. 99(10): p. 4317-4325. Galloway, N.R., et al., Basic anatomy and physiology of the eye, in Common Eye Diseases and their Management. 2016, Springer. p. 7-16.

Cox, W.V., A. Kupferman, and H.M. Leibowitz, Topically applied steroids in corneal disease: II. The role of drug vehicle in stromal absorption of dexamethasone. Archives of Ophthalmology, 1972. 88(5): p. 549-552.

Green, K. and S.J. DOWNS, Prednisolone phosphate penetration into and through the cornea. Investigative Ophthalmology \& Visual Science, 1974. 13(4): p. 316-319. Leibowitz, H.M. and A. Kupferman, Kinetics of topically administered prednisolone acetate: Optimal concentration for treatment of inflammatory keratitis. Archives of Ophthalmology, 1976. 94(8): p. 1387-1389. 
Flint, G.R. and D.J. Morton, Effect of derivatization of the bioavailability of 118. ophthalmic steroids: development of an in vitro method of evaluation. Archives of Ophthalmology, 1984. 102(12): p. 1808-1809.

McGhee, C., et al., Penetration of synthetic corticosteroids into human aqueous

119. humour. Eye, 1990. 4(3): p. 526-530.

Kristinsson, J.K., et al., Dexamethasone-cyclodextrin-polymer co-complexes in aqueous eye drops. Aqueous humor pharmacokinetics in humans. Investigative ophthalmology \& visual science, 1996. 37(6): p. 1199-1203.

Becker, B., Intraocular pressure response to topical corticosteroids. Investigative

121. Ophthalmology \& Visual Science, 1965. 4(2): p. 198-205.

Al-Amin, M., et al., Dexamethasone Loaded Liposomes by Thin-Film Hydration and Microfluidic Procedures: Formulation Challenges. International journal of molecular sciences, 2020. 21(5): p. 1611.

Elbialy, N.S., et al., Enhancement of the ocular therapeutic effect of prednisolone acetate by liposomal entrapment. J Biomed Nanotechnol, 2013. 9(12): p. 2105-16. CHAUDHARI, P.D. and U.S. DESAI, Formulation and evaluation of niosomal in situ gel of prednisolone sodium phosphate for ocular drug delivery. Int J App Pharm, 2019. 11(2): p. 97-116.

Raizman, M., Corticosteroid therapy of eye disease: fifty years later. Archives of 125 ophthalmology, 1996. 114(8): p. 1000-1001.

Hughes, P.M., et al., Topical and systemic drug delivery to the posterior segments. Advanced drug delivery reviews, 2005. 57(14): p. 2010-2032.

Hadayer, A. and S. Schaal, Delivery of steroids into the eye for the treatment of macular edema. Expert opinion on drug delivery, 2016. 13(8): p. 1083-1091.

Barar, J., A.R. Javadzadeh, and Y. Omidi, Ocular novel drug delivery: impacts of 128. membranes and barriers. Expert opinion on drug delivery, 2008. 5(5): p. 567-581. Kompella, U.B., R.S. Kadam, and V.H. Lee, Recent advances in ophthalmic drug 129. delivery. Therapeutic delivery, 2010. 1(3): p. 435-456.

Cunha-Vaz, J., The blood-retinal barrier in retinal disease. Journal-The Blood-Retinal Barrier in Retinal Disease, 2009.

Waite, D., et al., Posterior drug delivery via periocular route: challenges and 131. opportunities. Therapeutic delivery, 2017. 8(8): p. 685-699.

Kaufman, H.E., et al., Effect of the herpes simplex virus genome on the response of infection to corticosteroids. American journal of ophthalmology, 1985. 100(1): p. 114-118.

Urban Jr, R.C. and E. Cotlier, Corticosteroid-induced cataracts. Survey of 133. ophthalmology, 1986. 31(2): p. 102-110.

De Nijs, R., Glucocorticoid-induced osteoporosis: a review on pathophysiology and treatment options. Minerva medica, 2008. 99(1): p. 23.

Eisenstadt, W. and E. Cohen, Osteoporosis and compression fractures from 135. prolonged cortisone and corticotropin therapy. Annals of allergy, 1955. 13(3): p. 252. Boland, E.W., NONSPECIFIC ANTI-INFLAMMATORY AGENTS-Some Notes on Their Practical Application, Especially in Rheumatic Disorders. California medicine, 1964. 100(3): p. 145.

Stanbury, R.M. and E.M. Graham, Systemic corticosteroid therapy-side effects and their management. British Journal of Ophthalmology, 1998. 82(6): p. 704-708. Livanou, T., D. Ferriman, and V. James, Recovery of hypothalamo-pituitary-adrenal function after corticosteroid therapy. The Lancet, 1967. 290(7521): p. 856-859. Buchman, A.L., Side effects of corticosteroid therapy. Journal of clinical 139. gastroenterology, 2001. 33(4): p. 289-294. 
LEOPOLD, I.H. and H.S. KROMAN, Methyl-and fluoro-substituted prednisolones in

140.

the blood and aqueous humor of the rabbit: Concentrations. AMA Archives of

Ophthalmology, 1960. 63(6): p. 943-947.

Hyndiuk, R.A. and M.G. Reagan, Radioactive depot-corticosteroid penetration into

141.

monkey ocular tissue: I. Retrobulbar and systemic administration. Archives of

Ophthalmology, 1968. 80(4): p. 499-503.

Barza, M., Factors affecting the intraocular penetration of antibiotics. The influence

142.

of route, inflammation, animal species and tissue pigmentation. Scandinavian

journal of infectious diseases. Supplementum, 1978(14): p. 151-159.

Tchernitchiv, A., et al., Glucocorticoid localization by radioautography in the rabbit

eye following systemic administration of $3 \mathrm{H}$-dexamethasone. Investigative

ophthalmology \& visual science, 1980. 19(10): p. 1231-1236.

Hernandez, M., et al., Corneal-conjunctival uptake of topical 3H-dexamethasone in

the rabbit eye. Investigative ophthalmology \& visual science, 1981. 20(1): p. 120-

123.

Sherif, Z. and U. Pleyer, Corticosteroids in ophthalmology: past-present-future.

145.

Ophthalmologica, 2002. 216(5): p. 305-315.

$\mathrm{Yu}, \mathrm{W} .-\mathrm{K}$. , et al., Ocular adnexal IgG4-related disease: clinical features, outcome, and

146.

factors associated with response to systemic steroids. Japanese journal of

ophthalmology, 2015. 59(1): p. 8-13.

Wakefield, D., P. McCluskey, and R. Penny, Intravenous pulse methylprednisolone

147.

therapy in severe inflammatory eye disease. Archives of Ophthalmology, 1986.

104(6): p. 847-851.

Sulaiman, R.S., M. Kadmiel, and J.A. Cidlowski, Glucocorticoid receptor signaling in

148.

the eye. Steroids, 2018. 133: p. 60 - 66.

McGhee, C.N., S. Dean, and H. Danesh-Meyer, Locally administered ocular 149.

corticosteroids. Drug Safety, 2002. 25(1): p. 33-55.

Geroski, D.H. and H.F. Edelhauser, Transscleral drug delivery for posterior segment

disease. Advanced drug delivery reviews, 2001. 52(1): p. 37-48.

Raghava, S., M. Hammond, and U.B. Kompella, Periocular routes for retinal drug

delivery. Expert opinion on drug delivery, 2004. 1(1): p. 99-114.

Agban, Y., et al., Depot formulations to sustain periocular drug delivery to the 152

posterior eye segment. Drug discovery today, 2019. 24(8): p. P 1458-1469.

Olsen, T.W., et al., Human sclera: thickness and surface area. American journal of

153.

ophthalmology, 1998. 125(2): p. 237-241.

Olsen, T.W., et al., Human scleral permeability. Effects of age, cryotherapy, 154.

transscleral diode laser, and surgical thinning. Investigative ophthalmology \& visual

science, 1995. 36(9): p. 1893-1903.

Ambati, J., et al., Diffusion of high molecular weight compounds through sclera.

155.

Investigative ophthalmology \& visual science, 2000. 41(5): p. 1181-1185.

Wen, H., J. Hao, and S.K. Li, Influence of permeant lipophilicity on permeation across

human sclera. Pharmaceutical research, 2010. 27(11): p. 2446-2456.

Janoria, K.G., et al., Novel approaches to retinal drug delivery. Expert opinion on

drug delivery, 2007. 4(4): p. 371-388.

Castellarin, A. and D.J. Pieramici, Anterior segment complications following 158.

periocular and intraocular injections. Ophthalmology clinics of North America, 2004.

17(4): p. 583-90, vii.

Akduman, L., et al., Treatment of persistent glaucoma secondary to periocular

corticosteroids. American journal of ophthalmology, 1996. 122(2): p. 275-277.

Nozik, R.A., Orbital rim fat atrophy after repository periocular corticosteroid 160.

injection. American journal of ophthalmology, 1976. 82(6): p. 928-930. 
Weijtens, O., et al., Dexamethasone concentration in the subretinal fluid after a

subconjunctival injection, a peribulbar injection, or an oral dose. Ophthalmology,

2000. 107(10): p. 1932-1938.

Weijtens, O., et al., High concentration of dexamethasone in aqueous and vitreous

162.

after subconjunctival injection. American journal of ophthalmology, 1999. 128(2): p.

192-197.

Kompella, U.B., N. Bandi, and S.P. Ayalasomayajula, Subconjunctival nano-and

163.

microparticles sustain retinal delivery of budesonide, a corticosteroid capable of

inhibiting VEGF expression. Investigative ophthalmology \& visual science, 2003.

44(3): p. 1192-1201.

Leibowitz, H.M. and A. Kupferman, Periocular injection of corticosteroids: an

164.

experimental evaluation of its role in the treatment of corneal inflammation.

Archives of Ophthalmology, 1977. 95(2): p. 311-314.

Conrad, J.M. and J.R. Robinson, Mechanisms of anterior segment absorption of

165.

pilocarpine following subconjunctival injection in albino rabbits. Journal of

pharmaceutical sciences, 1980. 69(8): p. 875-884.

Amrite, A.C., H.F. Edelhauser, and U.B. Kompella, Modeling of corneal and retinal

166.

pharmacokinetics after periocular drug administration. Investigative ophthalmology

\& visual science, 2008. 49(1): p. 320-332.

Hosseini, K., et al., Pharmacokinetic study of dexamethasone disodium phosphate

167.

using intravitreal, subconjunctival, and intravenous delivery routes in rabbits. Journal

of ocular pharmacology and therapeutics, 2008. 24(3): p. 301-308.

McCartney, H., et al., An autoradiographic study of the penetration of 168.

subconjunctivally injected hydrocortisone into the normal and inflamed rabbit eye.

Investigative Ophthalmology \& Visual Science, 1965. 4(3): p. 297-302.

Holmberg, B.J. and D.J. Maggs, The use of corticosteroids to treat ocular 169.

inflammation. Veterinary Clinics: Small Animal Practice, 2004. 34(3): p. 693-705.

Pendergast, S.D., D. Eliott, and R. Machemer, Retinal toxic effects following 170.

inadvertent intraocular injection of Celestone Soluspan. Archives of Ophthalmology,

1995. 113(10): p. 1230-1231.

Fischer, C., Granuloma formation associated with subconjunctival injection of a 171.

corticosteroid in dogs. Journal of the American Veterinary Medical Association, 1979.

174(10): p. 1086-1088.

Herrero-Vanrell, R., et al., Sustained Back Of The Eye Delivery Following Sub-tenon

172.

Administration Of Dexamethasone-loaded PLGA Microspheres In Rabbits.

Investigative Ophthalmology \& Visual Science, 2012. 53(14): p. 477-477.

Das, D., S. Serasiya, and D. Misra, Complications and safety profile of posterior sub-

tenon triamcinolone injections in sclero-uveitis cases in a tertiary institute of

northeast India. Adv Ophthalmol Vis Syst, 2018. 8(6): p. 231-232.

Lafranco Dafflon, M., et al., Posterior sub-Tenon's steroid injections for the 174.

treatment of posterior ocular inflammation: indications, efficacy and side effects.

Graefe's archive for clinical and experimental ophthalmology, 1999. 237(4): p. 289-

295.

Cardillo, J.A., et al., Comparison of intravitreal versus posterior sub-Tenon's capsule

injection of triamcinolone acetonide for diffuse diabetic macular edema.

Ophthalmology, 2005. 112(9): p. 1557-1563.

Kim, M.W., et al., Effect of posterior subtenon triamcinolone acetonide injection on

diabetic macular edema refractory to intravitreal bevacizumab injection. Korean

Journal of Ophthalmology, 2016. 30(1): p. 25-31.

Weiss, J.L. and C.B. Deichman, A comparison of retrobulbar and periocular 177. anesthesia for cataract surgery. Archives of Ophthalmology, 1989. 107(1): p. 96-98. 
Ripart, J., et al., Peribulbar versus Retrobulbar Anesthesia for Ophthalmic SurgeryAn

178.

Anatomical Comparison of Extraconal and Intraconal Injections. Anesthesiology: The Journal of the American Society of Anesthesiologists, 2001. 94(1): p. 56-62.

Herschler, J., Intractable intraocular hypertension induced by repository 179.

triamcinolone acetonide. American journal of ophthalmology, 1972. 74(3): p. 501-

504.

Olsen, T.W., et al., Cannulation of the suprachoroidal space: a novel drug delivery

180. methodology to the posterior segment. American Journal of Ophthalmology, 2006.

142(5): p. 777-787. e2.

Soiberman, U., et al., Subconjunctival injectable dendrimer-dexamethasone gel for

the treatment of corneal inflammation. Biomaterials, 2017. 125: p. 38-53.

Gillies, M.C., et al., Safety of an intravitreal injection of triamcinolone: results from a

randomized clinical trial. Archives of ophthalmology, 2004. 122(3): p. 336-340.

Hussain, N., et al., Combination therapy of intravitreal triamcinolone and 183.

photodynamic therapy with verteporfin for subfoveal choroidal neovascularization.

Indian journal of ophthalmology, 2006. 54(4): p. 247.

Hartman, R.R. and U.B. Kompella, Intravitreal, subretinal, and suprachoroidal

184.

injections: evolution of microneedles for drug delivery. Journal of Ocular

Pharmacology and Therapeutics, 2018. 34(1-2): p. 141-153.

Olsen, T.W., et al., Pharmacokinetics of pars plana intravitreal injections versus

185

microcannula suprachoroidal injections of bevacizumab in a porcine model.

Investigative ophthalmology \& visual science, 2011. 52(7): p. 4749-4756.

Tetz, M., S. Rizzo, and A.J. Augustin, Safety of submacular suprachoroidal drug 186.

administration via a microcatheter: retrospective analysis of European treatment

results. Ophthalmologica, 2012. 227(4): p. 183-189.

Gilger, B.C., et al., Long-term outcome after implantation of a suprachoroidal

187.

cyclosporine drug delivery device in horses with recurrent uveitis. Veterinary

ophthalmology, 2010. 13(5): p. 294-300.

Rai, U.D.J., et al., The suprachoroidal pathway: a new drug delivery route to the back

188.

of the eye. Drug discovery today, 2015. 20(4): p. 491-495.

Seiler, G.S., et al., Effect and distribution of contrast medium after injection into the

anterior suprachoroidal space in ex vivo eyes. Investigative ophthalmology \& visual

science, 2011. 52(8): p. 5730-5736.

Clearside Biomedical, I. Clearside Biomedical revises NDA resubmission timeline and

190.

XIPERE ${ }^{T M}$ commercial partnership with Bausch Health. 2020 [cited August 2020.

Edelhauser, H.F., et al., Intraocular distribution and targeting of triamcinolone

191.

acetonide suspension administered into the suprachoroidal space. Investigative

Ophthalmology \& Visual Science, 2014. 55(13): p. 5259-5259.

Goldstein, D.A., et al., Suprachoroidal corticosteroid administration: a novel route

192.

for local treatment of noninfectious uveitis. Translational vision science \&

technology, 2016. 5(6): p. 14-14.

Patel, S.R., et al., Suprachoroidal drug delivery to the back of the eye using hollow

microneedles. Pharmaceutical research, 2011. 28(1): p. 166-176.

Patel, S.R., et al., Targeted administration into the suprachoroidal space using a

microneedle for drug delivery to the posterior segment of the eye. Investigative

ophthalmology \& visual science, 2012. 53(8): p. 4433-4441.

Gilger, B.C., et al., Treatment of acute posterior uveitis in a porcine model by 195.

injection of triamcinolone acetonide into the suprachoroidal space using

microneedles. Investigative ophthalmology \& visual science, 2013. 54(4): p. 2483-

2492. 
Kuriakose, T., et al., Intracameral amphotericin B injection in the management of

196. deep keratomycosis. Cornea, 2002. 21(7): p. 653-656.

Shah, T.J., M.D. Conway, and G.A. Peyman, Intracameral dexamethasone injection in the treatment of cataract surgery induced inflammation: design, development, and place in therapy. Clinical Ophthalmology (Auckland, NZ), 2018. 12: p. 2223.

Tan, D.T., et al., Randomized clinical trial of a new dexamethasone delivery system (Surodex) for treatment of post-cataract surgery inflammation. Ophthalmology, 1999. 106(2): p. 223-231.

Wang, B., et al., Efficacy and safety of intracameral triamcinolone acetonide to 199. control postoperative inflammation after phacotrabeculectomy. Journal of Cataract \& Refractive Surgery, 2013. 39(11): p. 1691-1697.

Simaroj, P., P. Sinsawad, and K. Lekhanont, Effects of intracameral triamcinolone 200. and gentamicin injections following cataract surgery. Journal of the Medical Association of Thailand, 2011. 94(7): p. 819.

Mamalis, N., et al., Toxic anterior segment syndrome. Journal of Cataract \& 201. Refractive Surgery, 2006. 32(2): p. 324-333.

Cunningham, M.A., J.L. Edelman, and S. Kaushal, Intravitreal steroids for macular edema: the past, the present, and the future. Survey of ophthalmology, 2008. 53(2): p. 139-149.

Doshi, R.R., S.J. Bakri, and A.E. Fung. Intravitreal injection technique. in Seminars in ophthalmology. 2011. Taylor \& Francis.

Mitra, A.K., B.S. Anand, and S. Duvvuri, Drug delivery to the eye. Advances in Organ Biology, 2005. 10: p. 307-351.

Durairaj, C., et al., Prediction of vitreal half-life based on drug physicochemical 205. properties: quantitative structure-pharmacokinetic relationships (QSPKR).

Pharmaceutical research, 2009. 26(5): p. 1236.

Beer, P.M., et al., Intraocular concentration and pharmacokinetics of triamcinolone acetonide after a single intravitreal injection. Ophthalmology, 2003. 110(4): p. 681686.

Graham, R.O. and G.A. Peyman, Intravitreal injection of dexamethasone: treatment of experimentally induced endophthalmitis. Archives of ophthalmology, 1974. 92(2): p. $149-154$.

Tano, Y., D. Chandler, and R. Machemer, Treatment of intraocular proliferation with intravitreal injection of triamcinolone acetonide. American journal of ophthalmology, 1980. 90(6): p. 810-816.

Mansoor, S., B.D. Kuppermann, and M.C. Kenney, Intraocular sustained-release 209. delivery systems for triamcinolone acetonide. Pharmaceutical research, 2009. 26(4): p. 770-784.

Zacharias, L.C., et al., Assessment of the differences in pharmacokinetics and 210. pharmacodynamics between four distinct formulations of triamcinolone acetonide. Retina, 2013. 33(3): p. 522-531.

Kuppermann, B.D., L.C. Zacharias, and M.C. Kenney, Steroid differentiation: the safety profile of various steroids on retinal cells in vitro and their implications for clinical use (an American Ophthalmological Society thesis). Transactions of the American Ophthalmological Society, 2014. 112: p. 116.

Thackaberry, E.A., et al., The safety evaluation of long-acting ocular delivery systems. Drug discovery today, 2019. 24(8): p. 1539-1550.

Razeghinejad, M.R. and L.J. Katz, Steroid-induced iatrogenic glaucoma. Ophthalmic research, 2012. 47(2): p. 66-80.

Lee, D., Intraocular implants for the treatment of autoimmune uveitis. Journal of 206. functional biomaterials, 2015. 6(3): p. 650-666. 
Chang-Lin, J.-E., et al., Pharmacokinetics and pharmacodynamics of a sustainedrelease dexamethasone intravitreal implant. Investigative ophthalmology \& visual science, 2011. 52(1): p. 80-86.

Haghjou, N., M. Soheilian, and M.J. Abdekhodaie, Sustained release intraocular drug

216. delivery devices for treatment of uveitis. Journal of ophthalmic \& vision research, 2011. 6(4): p. 317.

Cao, Y., et al., Recent advances in intraocular sustained-release drug delivery 217. devices. Drug discovery today, 2019. 24(8): p. P 1694-1700.

Jaffe, G.J., et al., Fluocinolone acetonide sustained drug delivery device to treat 218 severe uveitis. Ophthalmology, 2000. 107(11): p. 2024-2033.

Driot, J.-Y., et al., Ocular pharmacokinetics of fluocinolone acetonide after Retisert ${ }^{\text {TM }}$ intravitreal implantation in rabbits over a 1-year period. Journal of Ocular Pharmacology and Therapeutics, 2004. 20(3): p. 269-275.

Alimera Sciences, I., ILUVIEN ${ }^{\circledR}$ (fluocinolone acetonide intravitreal implant) $0.19 \mathrm{mg}$

220. product information, I. Alimera Sciences, Editor 2019, Alimera Sciences, Inc. Kane, F.E. and K.E. Green, Ocular pharmacokinetics of fluocinolone acetonide 221. following Iluvien implantation in the vitreous humor of rabbits. Journal of Ocular Pharmacology and Therapeutics, 2015. 31(1): p. 11-16.

Sanford, M., Fluocinolone acetonide intravitreal implant (Iluvien ${ }^{\circledR}$ ). Drugs, 2013. 73(2): p. 187-193.

Parekh, A., et al., Risk factors associated with intraocular pressure increase in patients with uveitis treated with the fluocinolone acetonide implant. JAMA ophthalmology, 2015. 133(5): p. 568-573.

Chen, T.H., S.M. Hariprasad, and V. Raiji, Update on Emerging Steroid-Based Local Treatments for Noninfectious Uveitis. Ophthalmic Surgery, Lasers and Imaging Retina, 2018. 49(11): p. 828-831.

Cholkar, K., et al., Novel strategies for anterior segment ocular drug delivery. Journal of ocular pharmacology and therapeutics, 2013. 29(2): p. 106-123.

Tamura, H., et al., Intravitreal injection of corticosteroid attenuates leukostasis and vascular leakage in experimental diabetic retina. Investigative ophthalmology \& visual science, 2005. 46(4): p. 1440-1444.

Peeters, L., et al., Vitreous: a barrier to nonviral ocular gene therapy. Investigative ophthalmology \& visual science, 2005. 46(10): p. 3553-3561.

Thakur, S.S., et al., Intravitreal drug delivery in retinal disease: are we out of our 228 depth? Expert opinion on drug delivery, 2014. 11(10): p. 1575-1590.

Thakur, A., R. Kadam, and U.B. Kompella, Trabecular meshwork and lens partitioning 229. of corticosteroids: implications for elevated intraocular pressure and cataracts. Archives of ophthalmology, 2011. 129(7): p. 914-920. Prata, A.I., P. Coimbra, and M.E. Pina, Preparation of dexamethasone ophthalmic 230. implants: a comparative study of in vitro release profiles. Pharmaceutical development and technology, 2018. 23(3): p. 218-224. Schmit-Eilenberger, V.K., A novel intravitreal fluocinolone acetonide implant 231. (Iluvien ${ }^{\circledR}$ ) in the treatment of patients with chronic diabetic macular edema that is insufficiently responsive to other medical treatment options: a case series. Clinical ophthalmology (Auckland, NZ), 2015. 9: p. 801.

Abraldes, M.J., M. Fernández, and F. Gómez-Ulla, Intravitreal triamcinolone in 232. diabetic retinopathy. Current diabetes reviews, 2009. 5(1): p. 18-25.

Renfro, L. and J.S. Snow, Ocular effects of topical and systemic steroids. 233. Dermatologic clinics, 1992. 10(3): p. 505-512. 
Tripathi, R.C., et al., Corticosteroid treatment for inflammatory bowel disease in 234. pediatric patients increases intraocular pressure. Gastroenterology, 1992. 102(6): p. 1957-1961.

David, D. and J. Berkowitz, Ocular effects of topical and systemic corticosteroids. The

235. Lancet, 1969. 294(7612): p. 149-151.

Krupin, T., et al., Uveitis in association with topically administered corticosteroid.

236. American journal of ophthalmology, 1970. 70(6): p. 883-885.

Armaly, M.F., Effect of corticosteroids on intraocular pressure and fluid dynamics: III.

237. Changes in visual function and pupil size during topical dexamethasone application. Archives of Ophthalmology, 1964. 71(5): p. 636-644.

Miller, D., J.D. Peczon, and C.G. Whitworth, Corticosteroids and functions in the 238. anterior segment of the eye. American journal of ophthalmology, 1965. 59(1): p. 3134.

Fel, A., E. Aslangul, and C.J. Le, Eye and corticosteroid's use. Presse medicale (Paris, France: 1983), 2012. 41(4): p. 414-421.

Becker, B., The side effects of corticosteroids. Investigative Ophthalmology \& Visual Science, 1964. 3(5): p. 492-497.

Haimovici, R., et al., Risk factors for central serous chorioretinopathy: a case-control study. Ophthalmology, 2004. 111(2): p. 244-249.

Aulakh, R. and S. Singh, Strategies for minimizing corticosteroid toxicity: a review. The Indian Journal of Pediatrics, 2008. 75(10): p. 1067-1073.

Salek, S.S., et al., Periocular triamcinolone acetonide injections for control of 243. intraocular inflammation associated with uveitis. Ocular immunology and inflammation, 2013. 21(4): p. 257-263.

Campochiaro, P.A., et al., Sustained delivery fluocinolone acetonide vitreous inserts provide benefit for at least 3 years in patients with diabetic macular edema.

Ophthalmology, 2012. 119(10): p. 2125-2132.

Goñi, F.J., et al., Elevated intraocular pressure after intravitreal steroid injection in diabetic macular edema: monitoring and management. Ophthalmology and therapy, 2016. 5(1): p. 47-61.

Fracs, R.W. and P.B. Fracs, Intravitreal triamcinolone and elevated intraocular 246. pressure. Australian and New Zealand journal of ophthalmology, 1999. 27(6): p. 431432.

Mansour, A., et al., Periocular corticosteroids in diabetic papillopathy. Eye, 2005.

19(1): p. 45-51.

Jamrozy-Witkowska, A., et al., [Complications of intravitreal injections--own 248.

experience]. Klinika oczna, 2011. 113(4-6): p. 127-131.

Gopal, L., M. Bhende, and T. Sharma, Vitrectomy for accidental intraocular steroid injection. Retina (Philadelphia, Pa.), 1995. 15(4): p. 295-299.

Rahman, I. and S. Ataullah, Retrobulbar hemorrhage after sub-Tenon's anesthesia. Journal of Cataract \& Refractive Surgery, 2004. 30(12): p. 2636-2637.

Purdy, E.P. and G.S. Ajimal, Vision loss after lumbar epidural steroid injection. 251.

Anesthesia \& Analgesia, 1998. 86(1): p. 119-122.

Fogla, R., S.K. Rao, and J. Biswas, Avoiding conjunctival necrosis after periocular 252.

depot corticosteroid injection. Journal of cataract and refractive surgery, 2000. 26(2): p. 163-164.

Jusufbegovic, D. and S. Schaal, Quiescent herpes simplex keratitis reactivation after intravitreal injection of dexamethasone implant. Retinal Cases and Brief Reports, 2017. 11(4): p. 296-297. 
Fassbender Adeniran, J.M., D. Jusufbegovic, and S. Schaal, Common and rare ocular side-effects of the dexamethasone implant. Ocular immunology and inflammation, 2017. 25(6): p. 834-840.

Smithen, L.M., et al., Intravitreal triamcinolone acetonide and intraocular pressure.

255. American journal of ophthalmology, 2004. 138(5): p. 740-743.

Garrott, H.M. and M.J. Walland, Clinical case notes: glaucoma from topical 256. corticosteroids to the eyelids. Clinical \& experimental ophthalmology, 2004. 32(2): p. 224-226.

Garbe, E., et al., Inhaled and nasal glucocorticoids and the risks of ocular 257. hypertension or open-angle glaucoma. Jama, 1997. 277(9): p. 722-727.

Beverstock, A. and A. Kelly, Severe acute ocular hypertension following pulsed 258. methylprednisolone for juvenile idiopathic arthritis. BMJ Case Reports CP, 2019. 12(5): p. e229803.

Covell, L.L., Glaucoma induced by systemic steroid therapy. American journal of

259. ophthalmology, 1958. 45(1): p. 108-109.

Fitzgerald, L.A., et al., Under pressure: an ocular complication of oral corticosteroid 260. therapy. BMJ case reports, 2012. 2012: p. bcr2012006955.

ARMALY, M.F., The heritable nature of dexamethasone-induced ocular hypertension. Archives of Ophthalmology, 1966. 75(1): p. 32-35.

Armaly, M. and B. Becker. Intraocular pressure response to topical corticosteroids. in Federation proceedings. 1965.

Becker, B. and K.A. Hahn, Topical corticosteroids and heredity in primary open-angle glaucoma. American journal of ophthalmology, 1964. 57(4): p. 543-551.

Armaly, M.F., Effect of corticosteroids on intraocular pressure and fluid dynamics: I. The effect of dexamethasone* in the normal eye. Archives of ophthalmology, 1963. 70(4): p. 482-491.

Becker, B. and D.W. Mills, Elevated intraocular pressure following corticosteroid eye drops. Jama, 1963. 185(11): p. 884-886.

BECKER, B., et al., Intraocular pressure and its response to topical corticosteroids in diabetes. Archives of Ophthalmology, 1966. 76(4): p. 477-483.

Clark, A.F., et al., Dexamethasone-induced ocular hypertension in perfusion-cultured human eyes. Investigative ophthalmology \& visual science, 1995. 36(2): p. 478-489.

Hernandez, M.R., et al., Glucocorticoid target cells in human outflow pathway: 268. autopsy and surgical specimens. Invest Ophthalmol Vis Sci, 1983. 24(12): p. 1612-6. Weinreb, R., E. Cotlier, and B.Y. Yue, The extracellular matrix and its modulation in the trabecular meshwork. Survey of ophthalmology, 1996. 40(5): p. 379-390. Clark, A.F., Basic sciences in clinical glaucoma: steroids, ocular hypertension, and glaucoma. Journal of glaucoma, 1995. 4(5): p. 354-369.

Lewis, D., A. Symons, and R. Ancill, The stabilization-lysis action of anti- 271. inflammatory steroids on lysosomes. Journal of Pharmacy and Pharmacology, 1970. 22(12): p. 902-908.

Spaeth, G.L., M.M. Rodrigues, and S. Weinreb, Steroid-induced glaucoma: A.

Persistent elevation of intraocular pressure B. Histopathological aspects.

Transactions of the American Ophthalmological Society, 1977. 75: p. 353.

Smith, C., Corticosteroid glaucoma: A summary and review of the literature. Am J

Med Sci, 1966. 252: p. 239-244.

Pleyer , U., P.G. Ursell, and P. Rama, Intraocular pressure effects of common topical steroids for post-cataract inflammation: are they all the same? Ophthalmol. Ther., 2013 (2): p. 55-72. 
Lam, D.S., et al., Ocular hypertensive and anti-inflammatory responses to different

dosages of topical dexamethasone in children: a randomized trial. Clinical \&

experimental ophthalmology, 2005. 33(3): p. 252-258.

Kwok, A.K., et al., Ocular-hypertensive response to topical steroids in children.

276.

Ophthalmology, 1997. 104(12): p. 2112-2116.

Kinoshita, S., et al., Marked intraocular pressure response to instillation of 277. corticosteroids in children. American journal of ophthalmology, 1991. 112(4): p. 450454.

Mindel, J.S., et al., Comparative ocular pressure elevation by medrysone, 278.

fluorometholone, and dexamethasone phosphate. Archives of Ophthalmology, 1980.

98(9): p. 1577-1578.

Francois, J., Corticosteroid glaucoma. Annals of ophthalmology, 1977. 9(9): p. 10751080.

Weinreb, R., et al., Acute effects of dexamethasone on intraocular pressure in 280. glaucoma. Investigative ophthalmology \& visual science, 1985. 26(2): p. 170-175.

Muchtar, S., et al., Ex-vivo permeation study of indomethacin from a submicron 281. emulsion through albino rabbit cornea. Journal of Controlled Release, 1997. 44(1): p. 55-64.

Cantrill, H.L., et al., Comparison of in vitro potency of corticosteroids with ability to raise intraocular pressure. American journal of ophthalmology, 1975. 79(6): p. 10121017.

Nuyen, B., R.N. Weinreb, and S.L. Robbins, Steroid-induced glaucoma in the 283. pediatric population. Journal of American Association for Pediatric Ophthalmology and Strabismus, 2017. 21(1): p. 1-6.

Donnenfeld, E.D., et al., A multicenter randomized controlled fellow eye trial of 284 . pulse-dosed difluprednate $0.05 \%$ versus prednisolone acetate $1 \%$ in cataract surgery. American journal of ophthalmology, 2011. 152(4): p. 609-617. e1.

Herschler, J., Increased intraocular pressure induced by repository corticosteroids. American journal of ophthalmology, 1976. 82(1): p. 90-93.

Kalina, P.H., J.C. Erie, and L. Rosenbaum, Biochemical quantification of 286. triamcinolone in subconjunctival depots. Archives of Ophthalmology, 1995. 113(7): p. 867-869.

Whitcup, S.M., et al., Pharmacology of corticosteroids for diabetic macular edema. Investigative ophthalmology \& visual science, 2018. 59(1): p. 1-12.

Parente, L., Deflazacort: therapeutic index, relative potency and equivalent doses versus other corticosteroids. BMC Pharmacology and Toxicology, 2017. 18(1): p. 1. Becker, B., Diabetes mellitus and primary open-angle glaucoma: the XXVII Edward Jackson Memorial Lecture. American journal of Ophthalmology, 1971. 71(1): p. 1-16. Podos, S.M., B. Becker, and W.R. Morton, High myopia and primary open-angle 290. glaucoma. American journal of ophthalmology, 1966. 62(6): p. 1039-1043.

Gaston, H., et al., Steroid responsiveness in connective tissue diseases. British 291. Journal of Ophthalmology, 1983. 67(7): p. 487-490.

Wilson, M., Epidemiology of chronic open-angle glaucoma. The glaucomas, 1996. 2: p. 753-768.

Haas, J.S. and R.H. Nootens, Glaucoma secondary to benign adrenal adenoma. 293. American journal of ophthalmology, 1974. 78(3): p. 497-500.

Huschle, O., et al., Glaucoma in central hypothalamic-hypophyseal Cushing 294. syndrome. Fortschritte der Ophthalmologie: Zeitschrift der Deutschen Ophthalmologischen Gesellschaft, 1990. 87(5): p. 453-456.

Stárka, L., R. Hampl, and J. Obenberger, Corticosterone in the aqueous humour of 295. the rabbit eye. Journal of steroid biochemistry, 1972. 3(1): p. 39-42. 
Starka, L., et al., The role of corticosteroids in the homeostasis of the eye. Journal of

296. steroid biochemistry, 1986. 24(1): p. 199-205.

Tielsch, J.M., et al., Racial variations in the prevalence of primary open-angle 297. glaucoma: the Baltimore Eye Survey. Jama, 1991. 266(3): p. 369-374.

Opatowsky, I., et al., Intraocular pressure elevation associated with inhalation and

298. nasal corticosteroids. Ophthalmology, 1995. 102(2): p. 177-179.

Spiliotopoulos, C., et al., The effect of nasal steroid administration on intraocular pressure. Ear, nose \& throat journal, 2007. 86(7): p. 394-395.

Katsushima, H., Corticosteroid-induced glaucoma following treatment of the 300 . periorbital region. Nippon Ganka Gakkai Zasshi, 1995. 99(2): p. 238-243.

CUBEY, R.B., Glaucoma following the application of corticosteroid to the skin of the

301. eyelids. British Journal of Dermatology, 1976. 95(2): p. 207-208.

Rosenblum, C., R.E. Dengler, and R.F. Geoffroy, Ocular absorption of 302. dexamethasone phosphate disodium by the rabbit. Archives of Ophthalmology, 1967. 77(2): p. 234-237.

Campochiaro, P.A., et al., Sustained ocular delivery of fluocinolone acetonide by an intravitreal insert. Ophthalmology, 2010. 117(7): p. 1393-1399. e3.

Black, R.L., et al., Posterior subcapsular cataracts induced by corticosteroids in 304. patients with rheumatoid arthritis. Jama, 1960. 174(2): p. 166-171.

Abdelkader, H., R.G. Alany, and B. Pierscionek, Age-related cataract and drug 305. therapy: opportunities and challenges for topical antioxidant delivery to the lens. J. Pharm. Pharmacol., 2015. 67: p. 537-550.

Karim, A., T. Jacob, and G. Thompson, The human lens epithelium; morphological and ultrastructural changes associated with steroid therapy. Experimental eye research, 1989. 48(2): p. 215-224.

Shun-Shin, G.A., et al., Dynamic nature of posterior subcapsular cataract. British journal of ophthalmology, 1989. 73(7): p. 522-527.

Jobling, A.I. and R.C. Augusteyn, What causes steroid cataracts? A review of steroidinduced posterior subcapsular cataracts. Clinical and experimental optometry, 2002. 85(2): p. 61-75.

Bodor, N. and P. Buchwald, Ophthalmic drug design based on the metabolic activity 306. of the eye: soft drugs and chemical delivery systems. The AAPS journal, 2005. 7(4): $p$. E820-E833.

Bucala, R., et al., Glucocorticoid-lens protein adducts in experimentally induced 310 steroid cataracts. Experimental eye research, 1985. 40(6): p. 853-863.

Bucala, R., et al., Nonenzymatic modification of lens crystallins by prednisolone 311 induces sulfhydryl oxidation and aggregate formation: in vitro and in vivo studies. Experimental eye research, 1985. 41(3): p. 353-363.

Harding, J.J., The lens: development, proteins, metabolism and cataract. The eye, 1984. 1: p. 207-492.

Hanania, N.A., K.R. Chapman, and S. Kesten, Adverse effects of inhaled 313. corticosteroids. The American journal of medicine, 1995. 98(2): p. 196-208.

Garbe, E., S. Suissa, and J. LeLorier, Association of inhaled corticosteroid use with cataract extraction in elderly patients. Jama, 1998. 280(6): p. 539-543.

Bilgihan, K., et al., Fluorometholone-Induced Cataract after Photoref ractive 315.

Keratectomy. Ophthalmologica, 1997. 211(6): p. 394-396.

Deshmukh, C., Minimizing side effects of systemic corticosteroids in children. Indian

Journal of Dermatology, Venereology, and Leprology, 2007. 73(4): p. 218.

Ohta, Y., et al., Anticataract action of vitamin E: its estimation using an in vitro steroid cataract model. Ophthalmic Literature, 1997. 1(50): p. 21. 
Abdelkader, H., et al., On the Anticataractogenic Effects of L-Carnosine: Is It Best Described as an Antioxidant, Metal-Chelating Agent or Glycation Inhibitor? Oxid. Med. Cell Longev., 2016. 2016: p. 3240261.

Samadi, A., Steroid-induced cataract, in Ocular Disease: Mechanism and 319. Management, L.A. Levin and D.M. Albert, Editors. 2010, SAUNDERS, Elsevier: USA. p. $250-257$.

Hengge, U.R., et al., Adverse effects of topical glucocorticosteroids. Journal of the 320. American Academy of Dermatology, 2006. 54(1): p. 1-15.

Moisseiev, E. and A. Loewenstein, Drug Delivery to the Posterior Segment of the Eye, in Macular Edema. 2017, Karger Publishers. p. 87-101.

Koay, P., The emerging roles of topical non-steroidal anti-inflammatory agents in 322 ophthalmology. The British journal of ophthalmology, 1996. 80(5): p. 480.

Flach, A., N. Jaffe, and W. Akers, The effect of ketorolac tromethamine in reducing postoperative inflammation: double-mask parallel comparison with dexamethasone. Annals of ophthalmology, 1989. 21(11): p. 407-411. Othenin-Girard, P., et al., Dexamethasone versus diclofenac sodium eyedrops to treat inflammation after cataract surgery. Journal of Cataract \& Refractive Surgery, 1994. 20(1): p. 9-12.

Abdelkader, H., et al., Cyclodextrin enhances corneal tolerability and reduces ocular toxicity caused by diclofenac. Oxid. Med. Cell Longev., 2018. 2018: p. 1-14.

Pereira, F., et al., Systemic absortion and adverse effects of topical ocular use of 326. ketorolac tromethamine and sodium diclofenac in New Zealand rabbits for 90 days. Arquivo Brasileiro de Medicina Veterinária e Zootecnia, 2019. 71(6): p. 1865-1872. Fukushima, A., et al., Therapeutic effects of $0.1 \%$ tacrolimus eye drops for refractory allergic ocular diseases with proliferative lesion or corneal involvement. $\mathrm{Br}$. J.

Ophthalmol. , 2014. 98: p. 1023-1027.

Eljarrat-Binstock, E. and A.J. Domb, lontophoresis: a non-invasive ocular drug 328. delivery. Journal of Controlled Release, 2006. 110(3): p. 479-489.

Kompella, U.B., et al., Ocular Drug Delivery: Nanotechnology, Physical and Chemical Methods, Vitreous Drug Binding, and Aging Eye. Journal of Ocular Pharmacology and Therapeutics, 2019.

Patane, M.A., et al., Ocular iontophoresis for drug delivery. Retina Today, 2011. 6: p. 64-66.

Patane, M., et al., Randomized, double-masked study of four iontophoresis dose 331. levels of EGP-437 in non-infectious anterior segment uveitis subjects. Investigative Ophthalmology \& Visual Science, 2010. 51(13): p. 5263-5263.

Ocular Therapeutix. Dextenza. 2016 [cited Accessed 20 July $2020 . \quad 332$.

; Available from: http://www.ocutx.com/pipeline/dexamethasone-punctum-plug. Bodor, N., E. Shek, and T. Higuchi, Improved delivery through biological membranes. 1. Synthesis and properties of 1-methyl-1, 6-dihydropyridine-2-carbaldoxime, a prodrug of $\mathrm{N}$-methylpyridinium-2-carbaldoxime chloride. Journal of medicinal chemistry, 1976. 19(1): p. 102-107.

Druzgala, P., W.-M. Wu, and N. Bodor, Ocular absorption and distribution of 334. loteprednol etabonate, a soft steroid, in rabbit eyes. Current eye research, 1991. 10(10): p. 933-937.

Samir, A., et al., Development of simultaneous quantification method of loteprednol etabonate (LE) and its acidic metabolites, and analysis of LE metabolism in rat. Xenobiotica, 2019. 49(5): p. 569-576.

Liu, R.f., et al. Efficacy of olopatadine hydrochloride $0.1 \%$, emedastine difumarate $0.05 \%$, and loteprednol etabonate $0.5 \%$ for Chinese children with seasonal allergic 
conjunctivitis: a randomized vehicle-controlled study. in International forum of allergy \& rhinology. 2017. Wiley Online Library.

Shulman, D.G., et al., A randomized, double-masked, placebo-controlled parallel 337. study of loteprednol etabonate $0.2 \%$ in patients with seasonal allergic conjunctivitis. Ophthalmology, 1999. 106(2): p. 362-369.

Comstock, T.L. and J.D. Sheppard, Loteprednol etabonate for inflammatory 338. conditions of the anterior segment of the eye: twenty years of clinical experience with a retrometabolically designed corticosteroid. Expert opinion on pharmacotherapy, 2018. 19(4): p. 337-353.

Lane, S.S. and E.J. Holland, Loteprednol etabonate $0.5 \%$ versus prednisolone acetate $1.0 \%$ for the treatment of inflammation after cataract surgery. Journal of Cataract \& Refractive Surgery, 2013. 39(2): p. 168-173.

Glogowski, S., et al., Prolonged exposure to loteprednol etabonate in human tear fluid and rabbit ocular tissues following topical ocular administration of lotemax gel, 0.5\%. Journal of Ocular Pharmacology and Therapeutics, 2014. 30(1): p. 66-73. Lomholt, J.A., J.K. Møller, and N. Ehlers, Prolonged persistence on the ocular surface of fortified gentamicin ointment as compared to fortified gentamicin eye drops. Acta Ophthalmologica Scandinavica, 2000. 78(1): p. 34-36.

Flach, A.J., Topical nonsteroidal antiinflammatory drugs in ophthalmology. International ophthalmology clinics, 2002. 42(1): p. 1-11.

O'Brien, T., Emerging guidelines for use of NSAID therapy to optimize cataract surgery patient care. Current medical research and opinion, 2005. 21(7): p. 11311137.

Cho, H., K.J. Wolf, and E.J. Wolf, Management of ocular inflammation and pain 344. following cataract surgery: focus on bromfenac ophthalmic solution. Clinical ophthalmology (Auckland, NZ), 2009. 3: p. 199.

Endo, N., et al., Efficacy of bromfenac sodium ophthalmic solution in preventing cystoid macular oedema after cataract surgery in patients with diabetes. Acta ophthalmologica, 2010. 88(8): p. 896-900.

Brennan, K., R. Brown, and C. Roberts, A comparison of topical non-steroidal antiinflammatory drugs to steroids for control of post cataract inflammation. Insight (American Society of Ophthalmic Registered Nurses), 1993. 18(1): p. 8-9, 11. Duan, P., Y. Liu, and J. Li, The comparative efficacy and safety of topical non- 347 steroidal anti-inflammatory drugs for the treatment of anterior chamber inflammation after cataract surgery: a systematic review and network metaanalysis. Graefe's Archive for Clinical and Experimental Ophthalmology, 2017. 255(4): p. 639-649.

Lane, S.S., et al., Nepafenac ophthalmic suspension $0.1 \%$ for the prevention and

treatment of ocular inflammation associated with cataract surgery. Journal of Cataract \& Refractive Surgery, 2007. 33(1): p. 53-58.

Gieser, D., et al., Flurbiprofen and intraocular pressure. Annals of ophthalmology, 1981. 13(7): p. 831-833.

Ayalasomayajula, S.P. and U.B. Kompella, Celecoxib, a selective cyclooxygenase-2 inhibitor, inhibits retinal vascular endothelial growth factor expression and vascular leakage in a streptozotocin-induced diabetic rat model. European journal of pharmacology, 2003. 458(3): p. 283-289.

Ayalasomayajula, S.P., A.C. Amrite, and U.B. Kompella, Inhibition of cyclooxygenase2 , but not cyclooxygenase-1, reduces prostaglandin $E 2$ secretion from diabetic rat retinas. European journal of pharmacology, 2004. 498(1-3): p. 275-278. 
Amrite, A.C., et al., Single periocular injection of celecoxib-PLGA microparticles inhibits diabetes-induced elevations in retinal PGE2, VEGF, and vascular leakage. Investigative ophthalmology \& visual science, 2006. 47(3): p. 1149-1160.

Shoughy, S.S., Topical tacrolimus in anterior segment inflammatory disorders. Eye 353. and Vision 2017. 4: p. 1-7.

Ames, P. and A. Galor, Cyclosporine ophthalmic emulsions for the treatment of dry 354. eye: a review of the clinical evidence. Clin. Investig. (Lond), 2015. 5: p. 267-285. 